\title{
OIP5, a target of miR-15b-5p, regulates hepatocellular carcinoma growth and metastasis through the AKT/mTORC1 and $\beta$-catenin signaling pathways
}

\author{
Hua Li ${ }^{1}$, Jun Zhang ${ }^{1}$, Mi-Jin Lee ${ }^{1}$, Goung-Ran Yu ${ }^{1}$, Xueji Han' ${ }^{2}$, Dae-Ghon Kim ${ }^{1}$ \\ ${ }^{1}$ Division of Gastroenterology and Hepatology, Department of Internal Medicine, The Research Institute of Clinical Medicine, \\ Biomedical Research Institute Chonbuk National University Medical School and Hospital, Jeonju, Jeonbuk, Republic of Korea \\ ${ }^{2}$ Department of Infectious Disease, Yanbian University Hospital, Yanji, Jilin Province, China \\ Correspondence to: Dae-Ghon Kim, email: daeghon@chonbuk.ac.kr
}

Keywords: OIP5, miR-15b-5p, hepatocellular carcinoma, tumor growth, metastasis

Received: June 29, 2016

Accepted: January 16, 2017

Published: February 08, 2017

\section{ABSTRACT}

Opa interacting protein 5 (OIP5) is upregulated in some types of human cancers, but the biological implications of its upregulation have not yet been clarified in human hepatocellular carcinoma (HCC). In this study, the signaling pathway downstream of OIP5 was analyzed by proteome kinase profiling. A putative microRNA targeting OIP5 was identified using a miRNA PCR array. Tumorigenicity and metastatic ability were examined in an orthotopic animal model. OIP5 expression was strongly detected in early and advanced tumors via gene expression profiling and immunohistochemical staining analyses. Cells with knockdown of OIP5 via target shRNA exhibited reduced hepatic mass formation and metastatic tumor nodules in an orthotopic mouse model. OIP5-induced AKT activation was mediated by both mTORC2 and p38/PTEN activation. AKT activation was linked to $\mathrm{mTORC1}$ and GSK-3 $\beta / \beta$-catenin signaling, which are primarily associated with tumor cell growth and metastasis, respectively. miR-15b$5 p$, which targets OIP5, efficiently inhibited OIP5-mediated mTORC1 and GSK-3 $\beta / \beta-$ catenin signaling. These findings suggest that OIP5 may be involved in HCC growth and metastasis and that miR-15b-5p inhibits OIP5-mediated oncogenic signaling in HCC.

\section{INTRODUCTION}

Opa interacting protein 5 (OIP5) encodes a 25-kDa protein with a coiled-coil domain that was found by yeast two-hybrid analysis to interact with Opa proteins [1]. OIP5 is also called Mis18beta and LINT-25. Mis18beta is essential for the structure and function of the centromere/ kinetochore, and accumulates specifically at telophase-G1 centromeres [2], forming a complex with C21orf45 and M18BP1. This protein also interacts with the retinoblastoma protein and regulates cell cycle progression via the E2F-Rb pathway [3]. OIP5 has been reported to be a testis-specific gene involved in gastric cancer [4]. In the fission yeast Schizosaccharomyces pombe, overexpression of OIP5 causes multi-septa formation and growth defects, both of which are considered cancer-related phenotypes. In addition, transient expression of OIP5 in NIH3T3 cells results in an increase in proliferation rate, highlighting its oncogenic properties [5]. Recently, OIP5 has also been reported to be upregulated in the tumors of colorectal cancer patients [6] and in female acute myeloid leukemia patients [7], implicating the protein as a potential therapeutic target for cancer [8]. Furthermore, it is a promising target for the development of new prognostic biomarkers and anti-cancer drugs in lung and esophageal cancers [9]. Despite the availability of a considerable amount of data, the precise function of OIP5 in human cancer, particularly hepatocellular carcinoma (HCC), remains unclear.

MicroRNAs (miRNAs) are endogenously expressed non-coding RNA oligonucleotides 21-23 bases in length that bind through topical sequence homology to the 3' untranslated region (UTR) of target messenger RNAs (mRNAs) and suppress gene expression [10]. Recent studies have implicated miR-15b regulation of proliferation and apoptosis in human osteoblastic cells and glioma cells through their targets, cyclin D1 and cyclin E $[11,12]$. 
In the present study, overexpression of OIP5 was found to be associated with HCC malignancy through activation of the AKT/mTORC1 and $\beta$-catenin signaling pathways. In addition, miR-15b-5p efficiently inhibited OIP5-mediated oncogenic signaling.

\section{RESULTS}

\section{OIP5 expression is mainly associated with tumor cell growth in $\mathrm{HCC}$ tissues and cell lines}

Microarray data derived from the Gene Expression Omnibus (GEO) database (GSE36411), containing 42 HCCs and corresponding non-tumor tissues, revealed that OIP5 expression in HCC tissue was significantly higher than expression in matched non-tumor tissues surrounding the liver (Figure 1A). In the two major sample clusters, genes from a non-tumor liver tissue group (NT; normal liver + liver cirrhosis) and a tumor tissue group (HCC; Edmondson grades I to IV) with a $P<0.05$ and a mean difference of expression $>1.5$ between the two groups were selected by unsupervised hierarchical clustering analysis. Next, using the same clustering analysis of the three subgroups (liver cirrhosis [LC], well-differentiated HCC [Edmondson grade I/II], and poorly-differentiated HCC [Edmondson grade III/IV]), we found that OIP5 expression was significantly higher in GI/II HCC than in $\mathrm{LC}$, and was higher in GIII/IV HCC than in GI/II HCC, implicating upregulation of OIP5 in HCC progression. We further statistically analyzed OIP5 mRNA levels via real-time RT-PCR in four groups of samples from the independent HCC cohorts, NL, LC, GI/II, and GIII/ IV (Figure 1B). The level of OIP5 mRNA significantly increased with worsening differentiation status, lack of fibrous capsule formation, microvessel invasion, intrahepatic metastasis, and advanced HCC stage (Supplementary Table 1).

A polyclonal rabbit antibody to OIP5 was tested for specific immunoreactivity by transfecting HEK293T cells with GFP- or c-Myc-tagged expression plasmids (Supplementary Figure 1A). OIP5 was highly expressed in $\mathrm{HCC}(75 \%)$ compared with non-tumor tissue, in 12 HCC/non-tumor tissue pairs (Supplementary Figure 1B). Immunohistochemical (IHC) staining for OIP5 in various $\mathrm{HCC}$ tissues revealed that OIP5 was moderately expressed in tumors compared to the much lower expression levels observed in surrounding non-tumor and normal liver tissues (Supplementary Figure 1C). OIP5 immunoreactivity was localized mainly in the nucleus, and less so in the cytoplasm of HCC cells. OIP5 was highly expressed in HepG2, Huh7, HLK2, and HKK2 cells, but was weakly or barely expressed in immortalized hepatocytes and other HCC cells (Supplementary Figure 1D). Immunofluorescence assays revealed that GFP-tagged OIP5 overlapped with OIP5 immunoreactivity and was prominently localized in the nucleus, and less abundant in the cytoplasm of HLK3 and HepG2 cells (Supplementary Figure 2A). An MTT assay revealed that the growth rate of HLK3 cells stably expressing OIP5 was greater than that of vector-control cells (Figure 1C). Accordingly, a colony generation assay revealed that OIP5 overexpression increased colony number by more than two-fold that of vector-control cells (Supplementary Figure 2B). In contrast, when OIP5 was stably knocked down in HLK2 cells using two different small hairpin RNA (shRNA) constructs, OIP5 silencing remarkably reduced colony numbers compared with control cells (Supplementary Figure 2C). We also examined the effect of OIP5 overexpression on the colony-forming capabilities of HLK3 and SH-J1 cells, and found that OIP5 expression significantly increased colony formation in soft agar compared with that by control cells (Figure 1D and Supplementary Figure 2D). MTT assay showed that the proliferation rate of HLK2 cells with OIP5 knockdown was prominently reduced (Figure 1E). Furthermore, anchorage-independent cell growth was barely detectable in HLK2 and Huh7 cells with OIP5 knockdown (Figure 1F and Supplementary Figure 2E). These results collectively demonstrated that OIP5 promotes the proliferation of HCC cells.

\section{OIP5-induced tumor growth and metastasis in vitro and in vivo}

To investigate the molecular mechanisms of OIP5mediated metastasis in $\mathrm{HCC}$, cell migration ability was analyzed via wound healing assay. HLK3 cells stably expressing OIP5 showed faster wound closure than did vector control cells (Figure 2A). In addition, OIP5 knockdown cells were significantly less likely to migrate to a wounded area than were parent or non-target control Huh7 and HLK2 cells (Figure 2B and Supplementary Figure 3A). In a Matrigel invasion chamber assay, OIP5 expression penetrated the matrix and colonized the bottom surface of the Matrigel-coated membrane to a larger extent than did vector control cells (Figure 2C). In contrast, Huh7 and HLK2 cells with OIP5 knockdown reduced cell invasiveness (Figure 2D and Supplementary Figure 3B). Collectively, OIP5 expression enhanced cell migration and invasiveness, whereas OIP5 suppression appeared to inhibit the migration and invasiveness of tumor cells in vitro. Finally, we examined changes in EMT marker expression in Huh7 cells with OIP5 knockdown. OIP5 knockdown substantially decreased the expression of mesenchymal markers (FN, $\alpha$-SMA, and VIM), and increased the expression of epithelial markers (DesI/II, E-cad, CK8, and CK18) (Figure 2E). OIP5 expression affected the expression of EMT markers and vice versa (Supplementary Figure 3C). These results suggest that OIP5 acts upstream of EMT changes.

Huh7 cells with OIP5 knockdown were orthotopically inoculated into the left lobe of mouse livers 
A

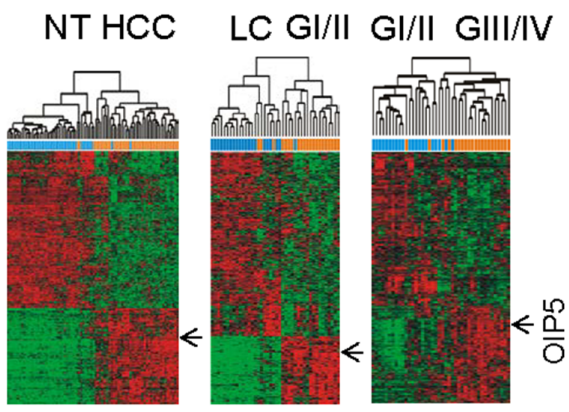

C
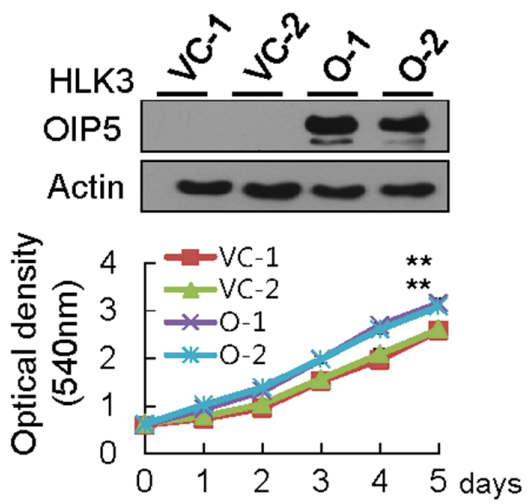

$\mathbf{E}$
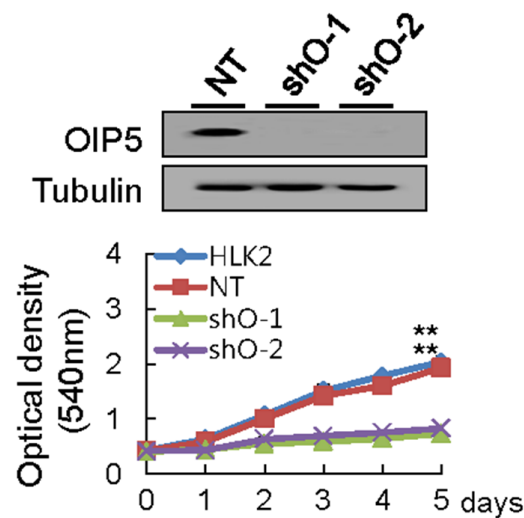

B

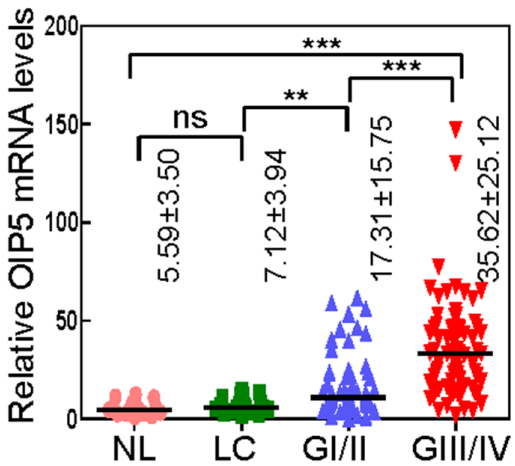

D

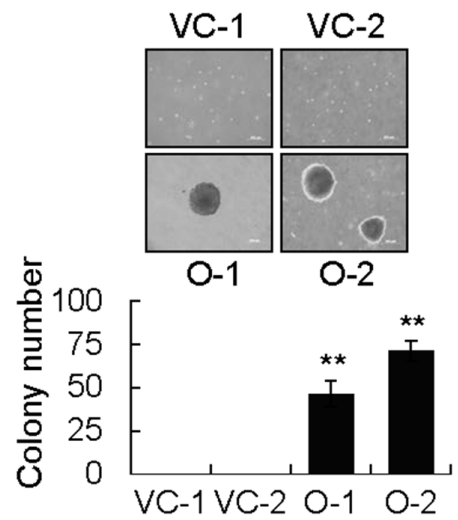

$\mathbf{F}$

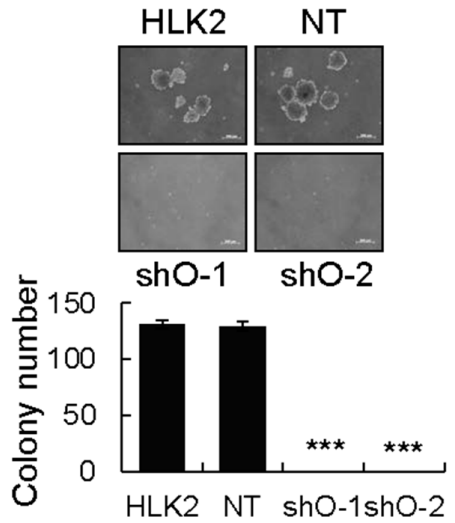

Figure 1: OIP5 expression in HCC tissues and cell lines modulates tumor cell growth. A. Unsupervised hierarchical clustering separated the samples into two main groups: a non-tumor group (NT; normal liver + liver cirrhosis, $\mathrm{n}=42$ ) and an HCC group (GI/II + GIII/ IV, $n=42$ ). Two subgroups were also present: a liver cirrhosis group (LC, $n=21$ ) and a well-differentiated HCC group (GI/II, $n=21$ ); a welldifferentiated HCC group (GI/II, $\mathrm{n}=21$ ) and a poorly differentiated HCC group (GIII/IV, $\mathrm{n}=21)$. OIP5 was a unique gene with a two-fold or greater difference in expression from the mean at $P<0.05$ based on the $t$-test for hierarchical clustering analysis. B. OIP5 mRNA levels were determined by real-time RT-PCR in four relevant groups of samples: normal liver (NL, $n=16$ ), liver cirrhosis ( $\mathrm{LC}, \mathrm{n}=19)$, Edmondson grade $\mathrm{I} / \mathrm{II}(\mathrm{GI} / \mathrm{II}, \mathrm{n}=58)$, and Edmondson grade III/IV (GIII/IV, $\mathrm{n}=74)$. Bars indicate medians. Values represent mean $\pm \mathrm{SD}$. $P$ values represent the results of Mann-Whitney $\mathrm{U}$ tests. The Kruskal-Wallis test was used for overall comparisons. $* * P<0.01 ; * * * P<0.001$. C. OIP5 expression in HLK3 cells (O) stably transfected with OIP5 expression plasmid evaluated via Western blot (upper panels). The proliferation of OIP5-expressing transfectants was evaluated by MTT assay (lower panels). Absorbance of the solution was measured at $540 \mathrm{~nm}$. Triplicate experiments with quadruplicate samples were performed. The values represent the mean \pm SD. ${ }^{* *} P<0.01$. VC, vector control. D. Soft agar colony formation assay on OIP5-expressing HLK3 cells. The colonies shown are two weeks old. Scale bar: $200 \mu \mathrm{m}$ (upper panels). Quantification of colony formation (lower panels). Each bar represents the mean $\pm \mathrm{SD}(\mathrm{n}=3) . * * P<0.01$. E. Knockdown of OIP5 (shO) by lentiviral delivery of OIP5 shRNA, evaluated by Western blot (upper panels). The proliferation of HLK2 cells with OIP5 knockdown was evaluated by MTT assay (lower panels). ${ }^{*} P<0.01$. NT, nontarget. F. Soft agar colony formation assay of HLK2 cells with OIP5 knockdown (upper panels). Scale bar: $200 \mu \mathrm{m}$. Quantification of colony formation (lower panels). Each bar represents the mean $\pm \mathrm{SD}(\mathrm{n}=3) .{ }^{* * *} P<0.001$. 
A

Oh

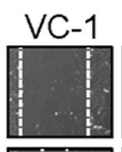

VC-2
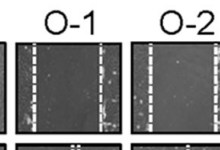

$48 h$
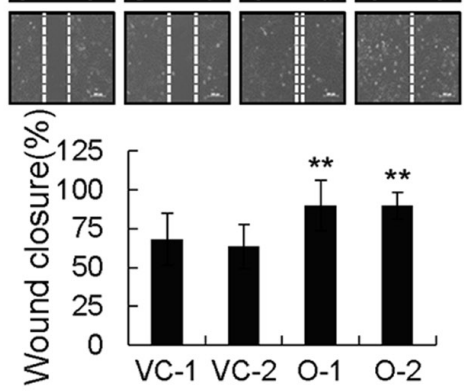

C

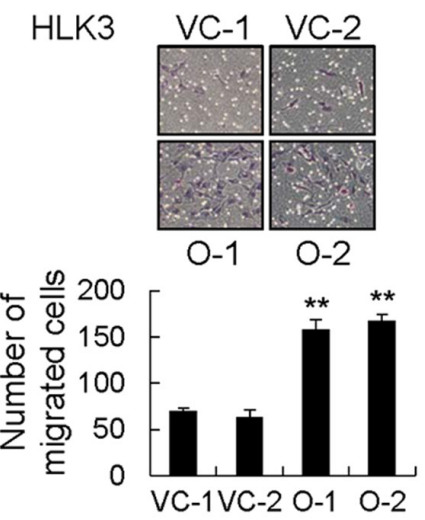

E

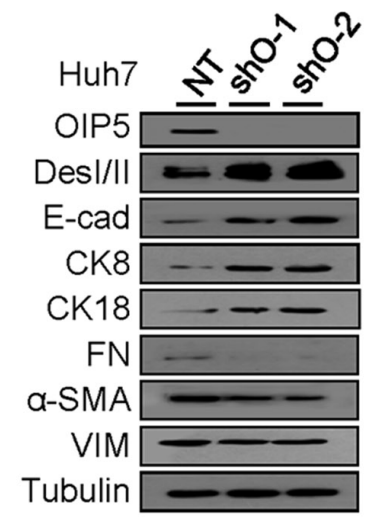

B

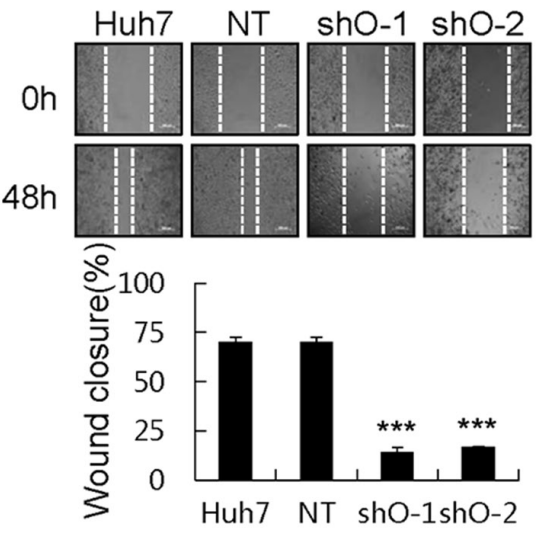

D

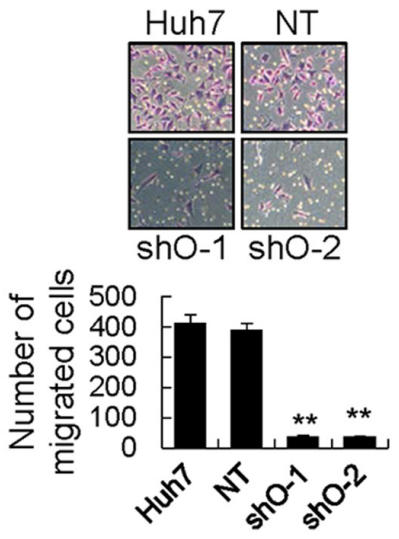

F

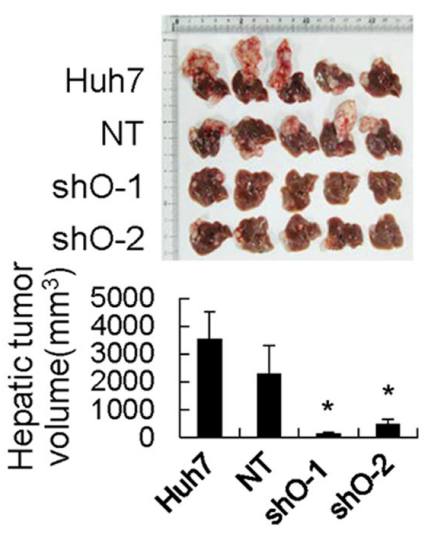

Figure 2: Modulation of migration and invasiveness by OIP5. A. Phase contrast images of HLK3 cells stably expressing OIP5 were taken $48 \mathrm{~h}$ after transduction in order to assess cell migration (upper panels). The results shown are representative of three independent experiments. Quantitative measurements of wound closure ability are shown (lower panels) $\left(\mathrm{n}=3\right.$, mean $\pm \mathrm{SD}$ ). ${ }^{* *} P<0.01$. B. Migratory ability was determined in Huh7 cells transduced with lentivirus encoding OIP5 shRNA via a wound healing assay. Phase contrast images were taken $48 \mathrm{~h}$ after transduction in order to assess cell migration (upper panels). The results shown are representative of three independent experiments. Quantitative measurements of wound closure ability are shown (lower panels) ( $\mathrm{n}=3$, mean $\pm \mathrm{SD}$ ). $* * * P<0.001$. C. Numerous stable OIP5 transfectants, but only a few vector control cells, had traversed the Matrigel-coated membrane after $48 \mathrm{~h}$ (upper panels). The cells that invaded were normalized to the viable cell mass on both sides of the membrane. Quantitative measurements of invasiveness are shown (lower panels) $(\mathrm{n}=3$, mean $\pm \mathrm{SD}) . * * P<0.01$. D. Photomicrographs of a modified Boyden chamber assay of Huh7 cells with OIP5 knockdown. The cells traversed the Matrigel-coated membrane after $48 \mathrm{~h}$ (upper panels). Cells that invaded were normalized to the viable cell mass on both sides of the membrane. Quantitative measurements of invasive ability are shown (lower panels) $(n=3$, mean \pm SD). ${ }^{* *} P<0.01$. E. Western blot analyses showed loss of mesenchymal markers and acquisition of epithelial marker proteins in Huh7 cells with OIP5 knockdown compared with non-target (NT) cells. The results shown are representative of three independent experiments. DesI/ II, desmoplakin I/II; E-cad, E-cadherin; CK, cytokeratin; FN, fibronectin; $\alpha$-SMA, alpha smooth muscle actin; VIM, vimentin. F. Massforming tumors and nodules in the liver of mice three weeks after intrahepatic inoculation of cells with or without OIP5 knockdown (upper panels). Quantification of nodules in the livers of mice (lower panels). Each bar represents the mean $\pm \mathrm{SD}$. ${ }^{*} P<0.05$. 
to examine whether OIP5 affects tumorigenicity. Massforming tumors with intrahepatic tumor nodules were easily detected in the livers of mice injected with parent or non-target control cells, whereas only a few intrahepatic tumor nodules were found in mice injected with OIP5knockdown cells (Figure 2F). OIP5 immunoreactivity was barely detected in hepatic tumors derived from cells with OIP5 knockdown (Supplementary Figure 4A). In addition, numerous mesenteric nodules were found in mice injected with parent or non-target control cells, whereas fewer mesenteric nodules were found in mice injected with OIP5-knockdown cells (Supplementary Figure 4B). These results suggest that OIP5 is substantially involved in tumor growth as well as in metastasis.

\section{OIP5 expression during the mitotic phase in $\mathrm{HCC}$ cells}

OIP5 immunoreactivity was prominent in mitotic cells. Therefore, we analyzed OIP5 expression in mitosis. OIP5 overexpression began in pre-prophase. After anaphase and telophase, its expression was reduced to its nadir during interphase (Figure 3A). A thymidineaphidicolin double-block experiment revealed cell cycledependent expression of OIP5 during the $\mathrm{G}_{2} / \mathrm{M}$-phase and early $G_{1}$ phase, which followed cyclin $E$ expression (Figure 3B). Next, to determine the exact role of OIP5 in cell cycle progression, cell cycle analysis revealed that OIP5 knockdown in Huh7 cells resulted in $\mathrm{G}_{2} / \mathrm{M}$ arrest (Figure 3C). To further examine this cell cycle arrest, levels of $\mathrm{G}_{2} / \mathrm{M}$ cell cycle-related proteins, such as $\mathrm{Cdc} 2$, Cdc25C, cyclin A, cyclin B1, and cyclin E, were examined by Western blotting (Figure 3D). The results indicated that phosphorylation and expression of $\mathrm{Cdc} 2$ and $\mathrm{Cdc} 25 \mathrm{C}$ were suppressed by the knockdown of OIP5. The Cdc2/cyclin B1 complex is essential for the $\mathrm{G}_{2} / \mathrm{M}$ transition, and cyclin $\mathrm{B} 1$ is also important for Cdc2 activity [13]. However, knockdown of OIP5 did not change the levels of cyclin A, cyclin B1, or cyclin E. Next, we determined whether OIP5 modulates activity of the promoters of cyclins and their associated proteins (Figure $3 \mathrm{E}$ ). OIP5 prominently upregulated the activity of the $\mathrm{Cdc} 25 \mathrm{C}$ promoter, but did not change the activity of the $\mathrm{Cdc} 2$ promoter, suggesting that OIP5 regulates these proteins transcriptionally or posttranscriptionally. In addition, to determine the molecular mechanism of OIP5 in cell death, we analyzed apoptotic cell death via flow cytometry in Huh7 cells with OIP5 knockdown (Supplementary Figure 5). OIP5 suppression significantly induced more apoptotic cell death than the nontarget control.

\section{Downstream AKT activation by OIP5}

To explore the mechanisms of OIP5 oncogenicity, we examined the activation of its downstream molecules using human phospho-MAPK arrays on lysates of HLK3 cells infected with adenovirus AdGFP/OIP5 or Ad-LacZ (Supplementary Figure 6A and 6B). Intriguingly, phosphorylation of AKT1 (S473), AKT2 (S474), and AKT3 (S472) was observed, as was panAKT phosphorylation. Transient expression of OIP5 by infection with Ad-OIP5 also increased the phosphorylation of AKT1 and AKT2 in HLK3 and SH-J1 cells (Figure 4A). Next, we observed that OIP5 knockdown resulted in a decrease in AKT1 and AKT2 phosphorylation in Huh7 and HLK2 cells (Figure 4B). Furthermore, immunofluorescence assay revealed that the cellular localization of OIP5 seemed to occur predominantly in the nucleus, whereas that of AKT occurred mainly in the cytoplasm of cells (Supplementary Figure 6C). Next, we determined whether OIP5 is involved in the activation of mTORC2, p38, PTEN, PI3K, PDK1, or ERK1/2 (Figure 4C), as activation of the PI3K/AKT and MAPK pathways is commonly implicated in $\mathrm{HCC}[14,15]$. We found that OIP5 increased mTORC2 activation and decreased p38 and PTEN activation compared to mock expression. However, this did not alter activation of PI3K, PDK1, and ERK molecules. Inactivation of p38 results in decreased expression of PTEN, which is linked to AKT activation [16]. Therefore, p38 MAPK/PTEN and mTORC2 may be independently involved in AKT activation.

\section{Nuclear translocation of $\beta$-catenin by AKT activation}

AKT activation occurs upstream of mTORC1 activation or downstream of mTORC2 [17, 18]. Accordingly, OIP5 expression efficiently results in the phosphorylation of mTORC2, mTORC1, 4E-BP1, and p70S6K in HLK3 cells (Figure 5A). AKT can regulate $\beta$-catenin-dependent transcription either by inhibiting GSK-3 $\beta$ or by directly phosphorylating and activating $\beta$-catenin $[19,20]$. To further determine the contribution of AKT activation to increased $\beta$-catenin signaling, we examined the phosphorylation levels of GSK-3 $\beta$ and $\beta$-catenin in HLK3 and SH-J1 cells after transient OIP5 expression by transduction with Ad-OIP5 (Figure $5 \mathrm{~B}$ and 5C). OIP5 expression significantly increased the phosphorylation levels of GSK-3 $\beta$ and $\beta$-catenin. Immunoblot analysis revealed that increased $\beta$-catenin expression was confined to the nuclear fraction of cells transduced with Ad-OIP5, and was less apparent in the cytoplasmic fraction of these cells (Figure 5D). Ectopic OIP5 expression enhanced the nuclear translocation of endogenous $\beta$-catenin (Supplementary Figure 7). Accordingly, OIP5 significantly increased TOP luciferase reporter activity (Figure 5E). Activated and mutant $\beta$-catenin prominently enhanced the phosphorylation of $\mathrm{Cdc} 2$ and $\mathrm{Cdc} 25 \mathrm{C}$ and intriguingly increased the transcript level of Cdc25C (Figure 5F). 
A

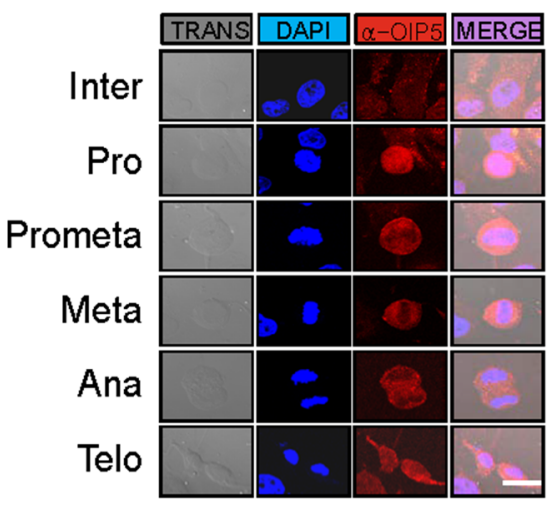

B

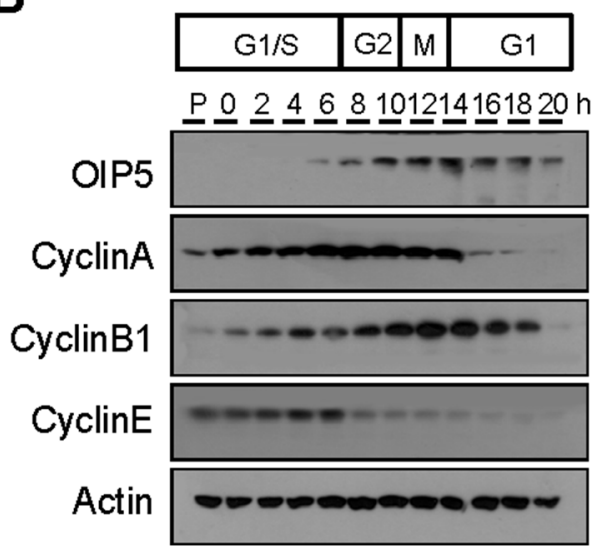

C
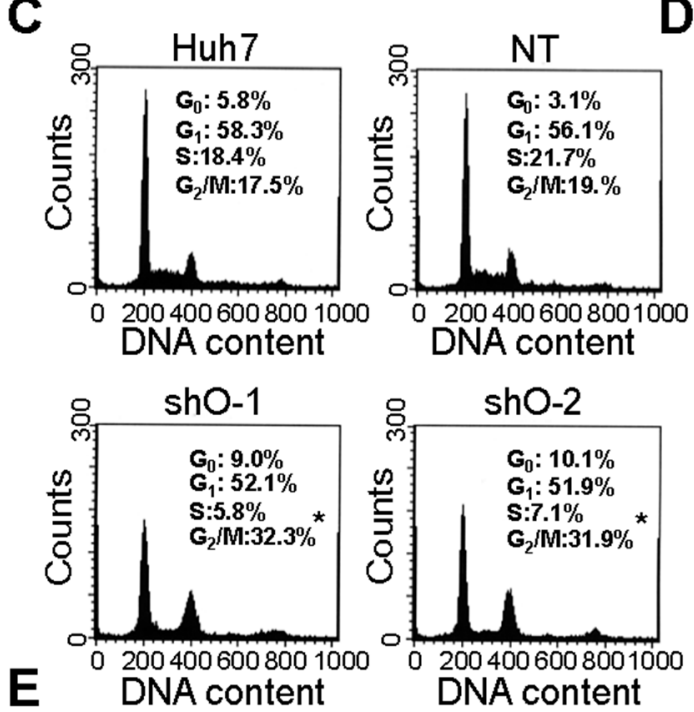
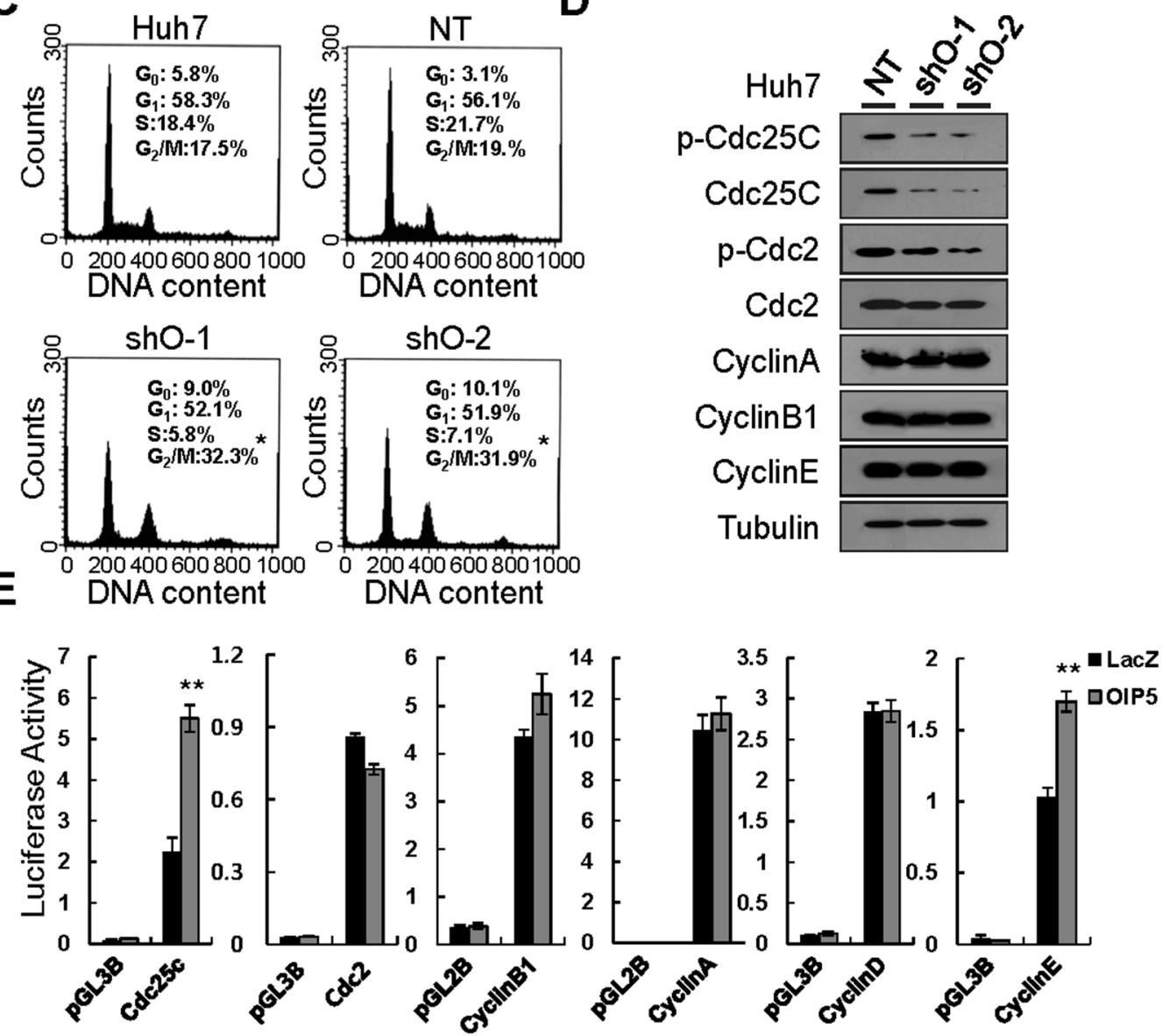

Figure 3: Analysis of the expression of OIP5 during cell cycle progression. A. Indirect immunofluorescence microscopy of HLK3 cells during cell cycle progression. Endogenous OIP5 expression at various stages of mitosis. Inter, interphase; Pro, prophase; Met, metaphase; Ana, anaphase; Telo, telophase. Trans, transmission. Bar, $20 \mu \mathrm{m}$. B. HeLa cells were synchronized in $\mathrm{G}_{1}$ using a thymidine/ aphidicolin double block and then released. Samples were collected for immunoblot analysis at $2 \mathrm{~h}$ intervals after release. The cells were extracted and probed with cyclin A, cyclin B1, cyclin E, and OIP5 antibodies. C. Cell cycle distribution was analyzed using flow cytometry after staining with propidium iodide (PI). Huh7 cells were transduced with lentiviruses carrying shRNA-targeting OIP5 (shO-1 and shO2) as well as non-targeting shRNA (NT). ${ }^{*} P<0.05$. $(\mathrm{n}=3)$. D. Representative immunoblots showing that OIP5 knockdown changed the expression of $\mathrm{Cdc} 2$ and $\mathrm{Cdc} 25 \mathrm{C}$, but not the expression of cyclin A, cyclin B1, or cyclin E in Huh7 cells. The immunoblot was probed with the indicated antibodies. Tubulin was used as a loading control. E. Promoter activities of cyclins and cyclin-associated proteins in response to OIP5 expression. Two independent quadruplicate experiments were performed. The values represent the mean $\pm \mathrm{SD}$. ${ }^{* *} P<0.01$. 


\section{OIP5-mediated tumor growth and metastasis via mTORC1 and $\beta$-catenin}

To examine the role of these pathways in tumor cell growth and metastatic ability, we measured cell growth in OIP5-expressing HLK3 cells treated with the mTORC1 inhibitor rapamycin (RPM, $100 \mathrm{nM}$ ) or the $\beta$-catenin inhibitor cardamonin (CDM, $10 \mu \mathrm{M})$. RPM substantially inhibited OIP5-dependent tumor cell growth, but had a smaller effect on OIP5-independent tumor cell growth (Figure 6A). CDM only partially inhibited OIP5dependent tumor cell growth. RPM treatment induced significant $\mathrm{G}_{1} / \mathrm{S}$ arrest, while $\mathrm{CDM}$ treatment caused $\mathrm{G}_{2} / \mathrm{M}$ arrest (Supplementary Figure 8A). We also analyzed the expression or activation of cyclins and their associated proteins in HLK3 cells after treatment with either RPM or CDM following transient OIP5 expression by transduction with Ad-OIP5. RPM increased p21 in Ad-OIP5-infected
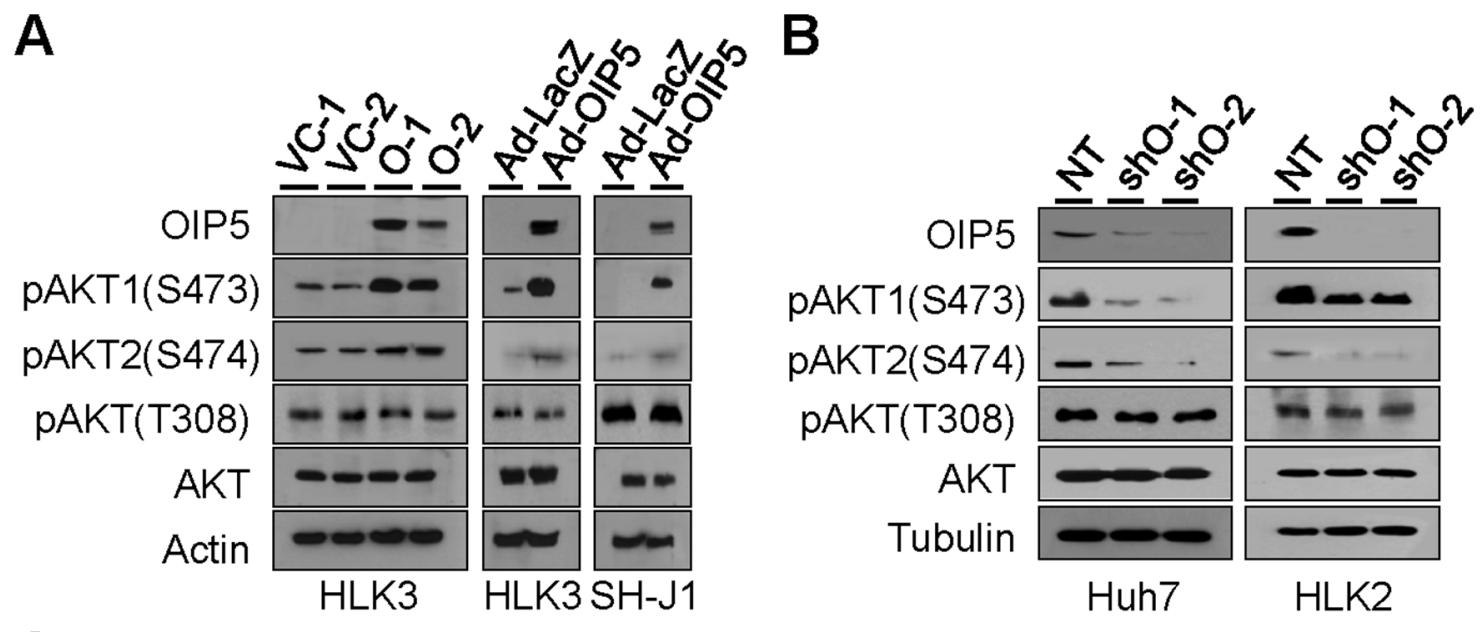

C
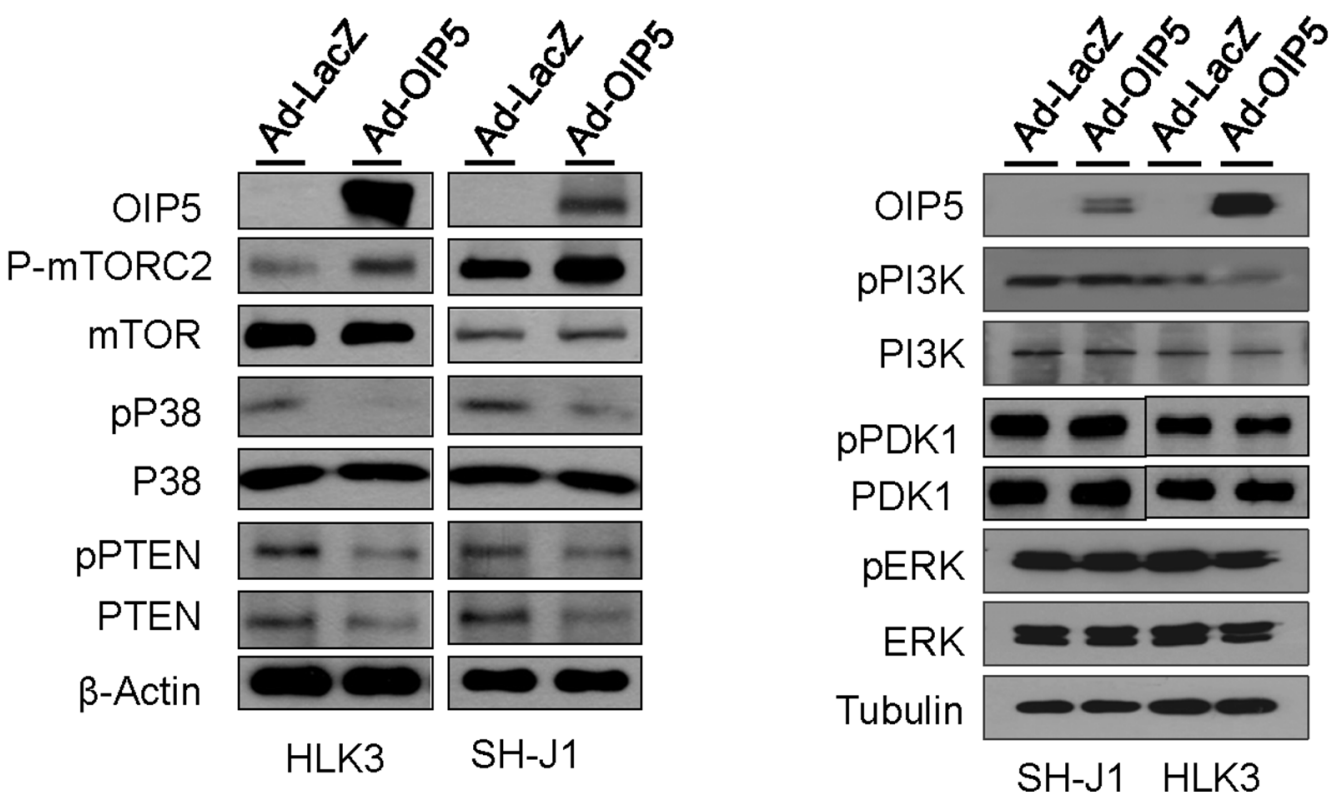

Figure 4: Phosphorylation of AKT by OIP5. A. Phosphorylation of AKT in stable OIP5 transfectants of HLK3 cells compared to vector control cells, and in HLK3 and SH-J1 cells transiently infected with Ad-OIP5 compared to Ad-LacZ control cells. B. Change in AKT phosphorylation in Huh7 and HLK2 cells by OIP5 knockdown via lentiviral delivery of shRNA. C. Activation of mTORC2, and inactivation of $\mathrm{p} 38$ and PTEN in HLK3 or SH-J1 cells transiently infected with Ad-OIP5 or Ad-LacZ adenovirus $(\mathrm{n}=3)$. Activation levels of PI3K, PDK1, and ERK did not change in SH-J1 or HLK3 cells transiently infected with Ad-OIP5 or Ad-LacZ adenovirus ( $\mathrm{n}=3$ ). 
A

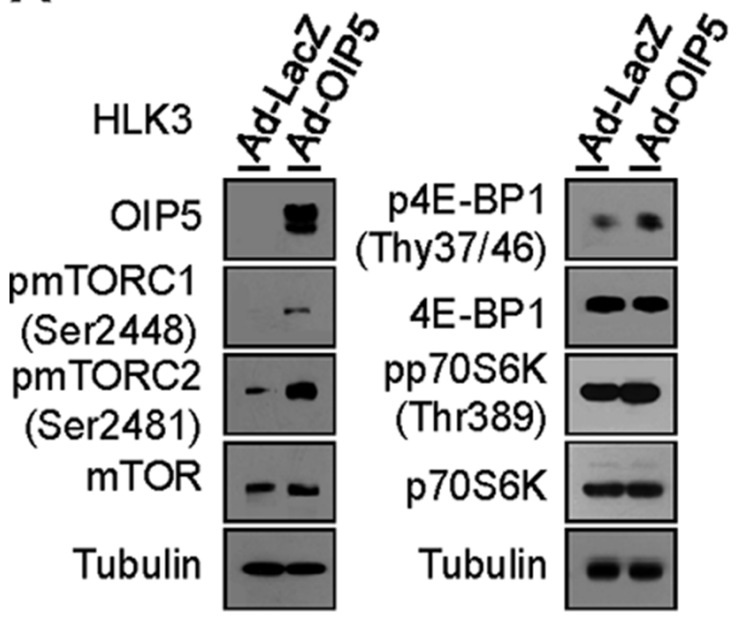

B

C

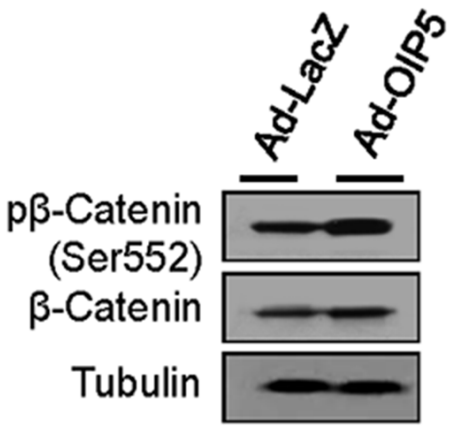

$\mathbf{E}$

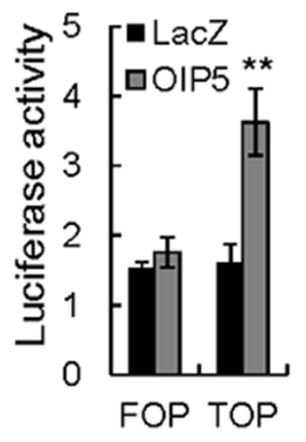

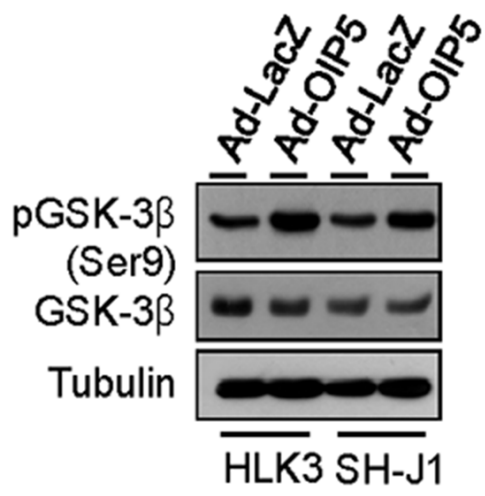

D

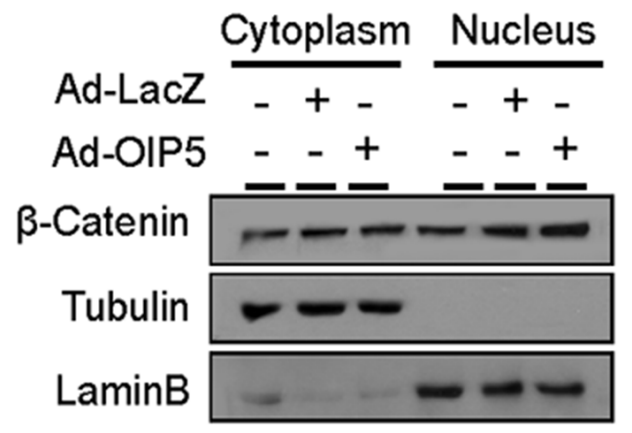

$\mathbf{F}$

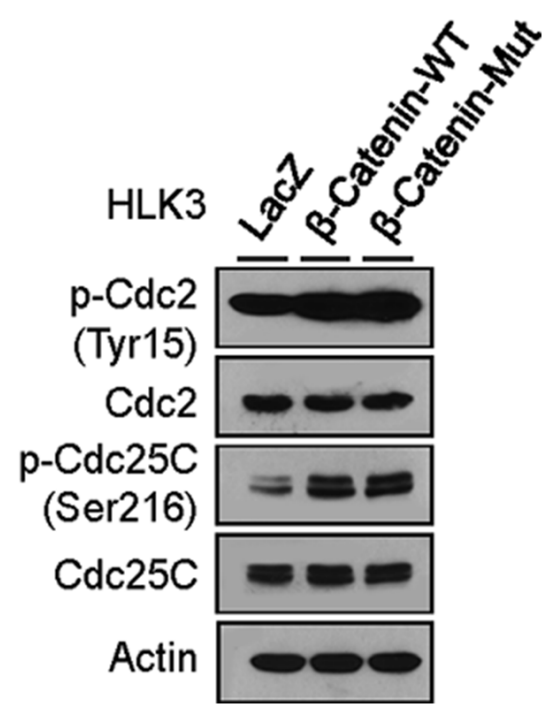

Figure 5: Activation of the mTORC1 and $\boldsymbol{\beta}$-catenin signaling pathways by OIP5. A. Activation of $\mathrm{mTORC} 1$ in HLK3 cells transiently infected with Ad-OIP5 compared to Ad-LacZ control cells on Western blot analysis. B. Phosphorylation of GSK-3 $\beta$ by OIP5 in HLK3 and SH-J1 cells transiently infected with Ad-OIP5 or Ad-LacZ adenovirus $(n=3)$. C. Phosphorylation of $\beta$-catenin at the S552 site by OIP5 in HLK3 cells transiently infected with Ad-OIP5 or Ad-LacZ adenovirus $(\mathrm{n}=3)$. D. Immunoblot analysis of nuclear and cytoplasmic levels of $\beta$-catenin in HLK3 cells transiently infected with Ad-OIP5 or Ad-LacZ adenovirus $(n=3)$. E. TCF/LEF-dependent transcriptional activity of $\beta$-catenin in HEK293T cells transfected with TOP/FOP flash reporter plasmids. Assays of relative luciferase activity in cells were performed $(\mathrm{n}=3)$. Each bar represents mean $\pm \mathrm{SD}$. $* * P<0.01$. F. Changes in Cdc2 and Cdc25C activation by $\beta$-catenin in HLK3 cells. Immunoblots were probed with the indicated antibodies. 
A

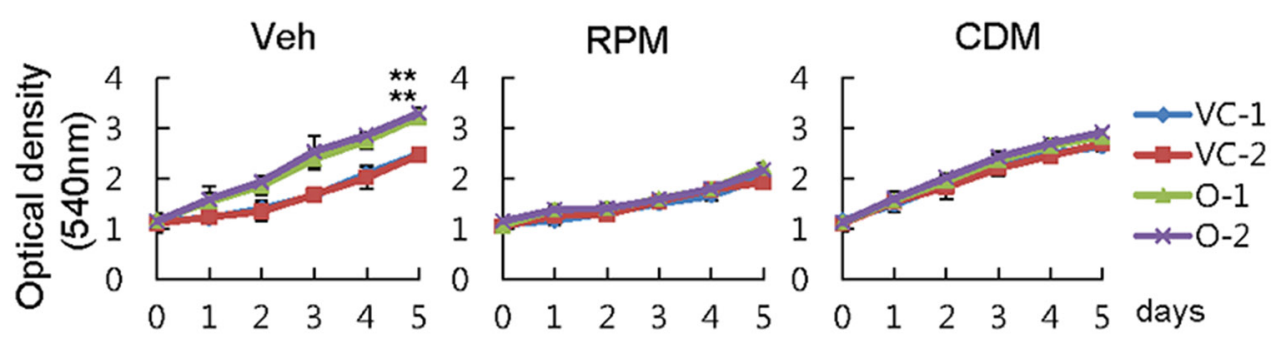

B
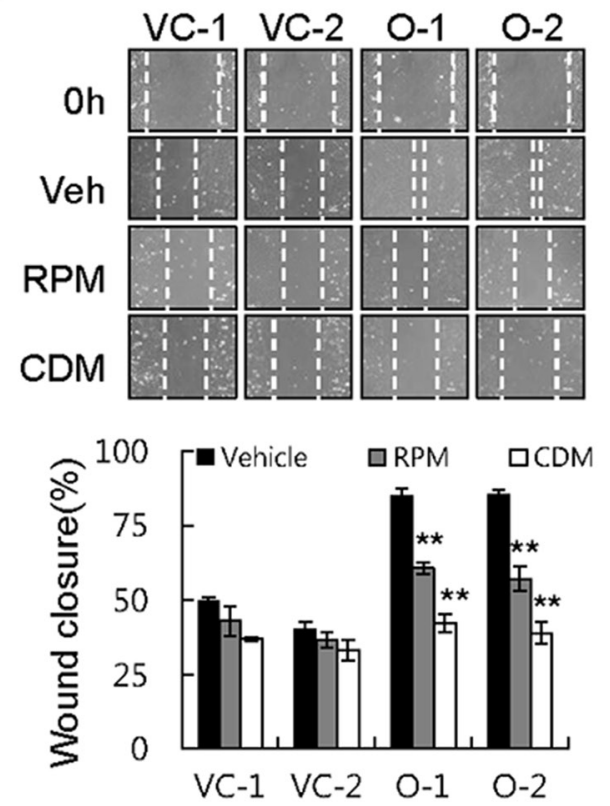

C
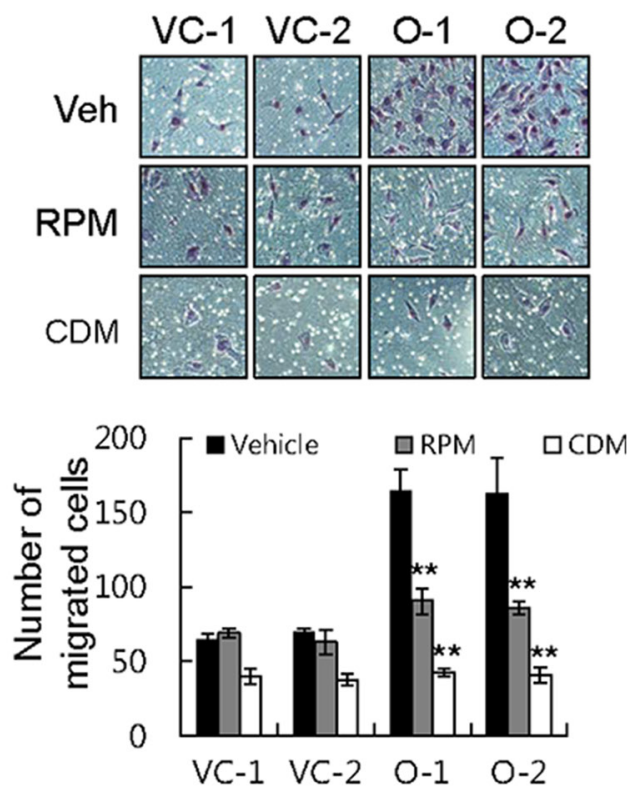

D

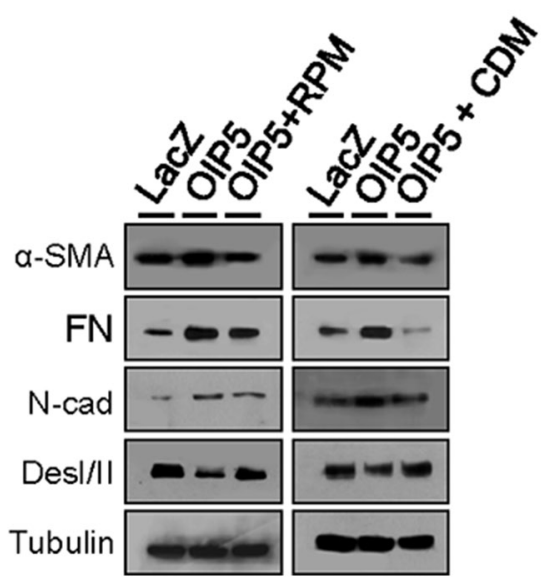

Figure 6: Inhibition of tumor cell growth and metastatic ability by rapamycin or cardamonin. A. Growth inhibition of OIP5 transfectants treated with rapamycin (RPM, $100 \mathrm{nM})$, cardamonin (CDM, $10 \mu \mathrm{M})$, or vehicle (Veh). Cell growth was measured by MTT assay five days after the cells were seeded on 24 -well plates $\left(2 \times 10^{4}\right.$ cells/well). Each value represents the mean \pm SD. $* * P<0.01$. B. A wound healing assay demonstrated substantial inhibition of OIP5-mediated wound closure by RPM (100 nM) or CDM (10 $\mu$ M) (upper panels). Quantitative measurements are shown (lower panels). Each bar represents the mean $\pm \mathrm{SD}(\mathrm{n}=3)$. $* * P<0.01$. C. A Matrigel assay showed that the invasiveness of OIP5 transfectants was inhibited by CDM $(10 \mu \mathrm{M})$, but less so by RPM (100 nM) or vehicle (upper panels). Quantitative measurements are shown (lower panels). Each bar represents the mean $\pm \mathrm{SD}(\mathrm{n}=3)$. ** $P<0.01$. D. Change in EMT marker protein expression by treatment with either RPM or CDM in HLK3 cells transiently infected with Ad-OIP5 or Ad-LacZ adenovirus ( $\mathrm{n}=3$ ). 
HLK3 cells, despite decreasing CDK2, CDK4, and CDK6 expression in the same cells (Supplementary Figure 8B). CDM significantly decreased the expression and phosphorylation of $\mathrm{Cdc} 25 \mathrm{C}$, and increased cyclin B1 expression, in Ad-OIP5-infected HLK3 cells (Supplementary Figure 8C). In a wound healing assay, CDM largely inhibited both OIP5-mediated wound closure (Figure 6B) and OIP5-mediated transwell invasion ability (Figure 6C). RPM, however, caused only partial inhibition of wound repair and invasion ability. These results suggest that the $\mathrm{AKT} / \mathrm{mTORC} 1$ pathway plays a major role in regulating tumor cell growth, while the AKT/ $\beta$-catenin pathway is involved in modulating metastatic ability. However, the AKT/mTORC1 and AKT/ $\beta$-catenin pathways also appeared to have partially overlapping functions. Finally, we evaluated changes in the level of the OIP5-mediated EMT marker via treatment with either RPM or CDM (Figure 6D). RPM and CDM similarly inhibited the expression of OIP5-mediated mesenchymal markers, including $\alpha$-SMA, FN, and N-cadherin, while increasing the expression of the epithelial marker Des I/II.

\section{OIP5 is a direct target of $\mathrm{miR}-15 b-5 p$}

To identify miRNAs whose expression correlates negatively with OIP5 expression, we performed an miRNA PCR array and identified miRNAs that were differentially expressed between low OIP5-expressing HLK3 cells and high OIP5-expressing Huh7 cells (Supplementary Figure 9A). Twenty-five miRNAs had lower expression in the HCC Huh7 cell line than in the immortalized HLK3 cell line (Supplementary Table 2). Of these, 15 miRNAs had significantly lower expression ( $>2$-fold, $P<0.05$; Supplementary Figure 9B). Using TargetScan and the miRanda database, we identified miR-15b-5p as a potential OIP5 regulator in HCC cells (Supplementary Figure 9C). Only miR-15b-5p was relatively elevated in HLK 3 cells and lower in Huh7 cells. Furthermore, whether endogenous OIP5 is regulated by miR-15b-5p in other HCC cells was investigated. Real-time PCR revealed that OIP5 mRNA levels were inversely correlated with miR$15 b-5 p$ levels in 3 immortalized liver cell lines and 13 HCC cell lines (Supplementary Figure 9D). Accordingly, mRNA and protein levels of OIP5 were measured in HLK3 and Huh7 cells following transfection with miR15b-5p mimic and anti-miR-15b-5p. OIP5 mRNA and protein levels were decreased in HLK3 and Huh7 cells transfected with miR-15b-5p overexpression, while increased OIP5 mRNA and protein levels were observed in cells transfected with miR-15b-5p silencing (Figure 7A and $7 \mathrm{~B}$ ). miR-15b-5p also regulated OIP5 downstream protein $\mathrm{mTORC} 1$ and $\beta$-catenin activation. Using the miRNA database, we found that miR-15b-5p is predicted to bind to the OIP5 3'UTR (Figure 7C). A dual-luciferase assay demonstrated a significant reduction in luciferase activities after cotransfection of miR-15b-5p and the wild type pGL3-OIP5 3'UTR reporter, while a significant increase in luciferase activity after cotransfection of anti-miR-15b-5p and the wild-type pGL3-OIP5 3'UTR reporter, but not after cotransfection of a mutant pGL3OIP5 3'UTR reporter (Figure 7D). Next, we measured miR-15b-5p levels in cells during the cell division cycle and found they were inversely regulated in a cyclic manner compared to OIP5 mRNA levels (Supplementary Figure 10). These results demonstrated that miR-15b-5p directly regulates OIP5. The schematic model demonstrated that OIP5 regulates tumor growth and metastasis through AKT activation, which is mediated by both mTORC2 activation and $\mathrm{p} 38 / \mathrm{PTEN}$ inactivation. AKT activation is linked to the downstream signaling pathway of both mTORC1 and $\beta$-catenin activation (Figure 7E).

\section{DISCUSSION}

OIP5 is highly expressed during the mitotic phase of the cell cycle. OIP5 expression is increased in preprophase and peaks in metaphase, while OIP5 knockdown mediates cell cycle arrest in the $\mathrm{G}_{2} / \mathrm{M}$ phase and apoptotic cell death. This knockdown experiment demonstrated that OIP5 was associated with the regulation and activation of cyclin-dependent kinase Cdc2 and phosphatase Cdc25C. ERK-MAP kinases were recently reported to be directly involved in activating $\mathrm{Cdc} 25 \mathrm{C}$ during the $\mathrm{G}_{2} / \mathrm{M}$ transition [21]. The simultaneous activation of the MAP kinase and AKT pathways in HBV-replicating hepatocytes resulted in dysregulation of cell cycle control, leading to malignant transformation associated with chronic hepatitis $\mathrm{B}$ infection [22]. In the present study, OIP5 expression enhanced AKT activation through the mTORC2 and p38/ PTEN signaling pathways. These results suggest that OIP5 expression is correlated with the mitotic proliferation of tumor cells, and that OIP5 knockdown-mediated inhibition of tumor cell growth causes accumulation of $\mathrm{G}_{2} / \mathrm{M}$ phase cell cycle regulators via OIP5/AKT signaling. Interestingly, our data also demonstrated that OIP5 knockdown induced apoptotic cell death, as reported previously [23].

Activation of AKT results in the phosphorylation of a number of downstream substrates, such as glycogen synthase kinase (GSK3), Bad, caspase 9, and forkhead transcription factors Raf, I $\mathrm{B}$ kinase, and phosphodiesterase 3B [24]. GSK3, one of the principal physiological substrates of AKT, is a ubiquitously expressed serine/threonine protein kinase that was initially identified as an enzyme that regulates glycogen synthesis in response to insulin $[25,26]$. GSK-3 $\beta$ plays an important role in the WNT pathway by regulating the degradation of $\beta$-catenin $[27,28]$. WNT signaling is implicated in proliferation, differentiation, embryogenesis, and tumorigenesis [29]. $\beta$-catenin is then translocated into the nucleus where it acts as a transcription factor for several genes, including Myc 
A

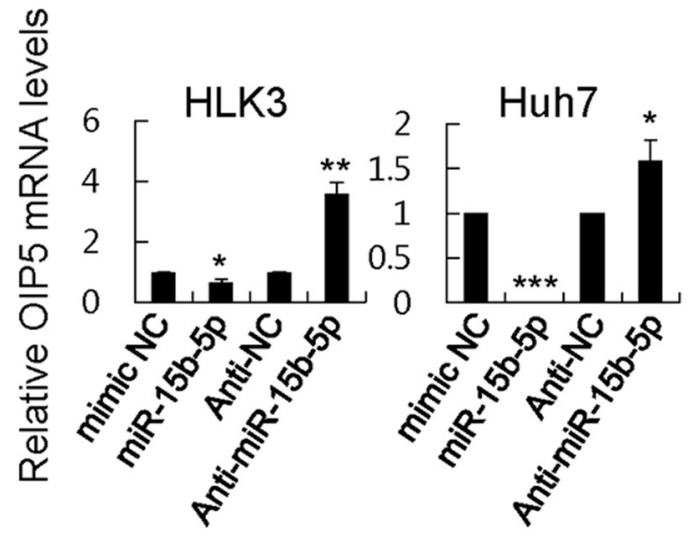

C

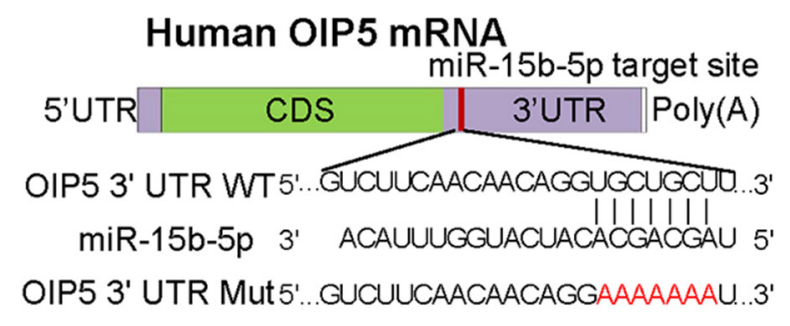

D

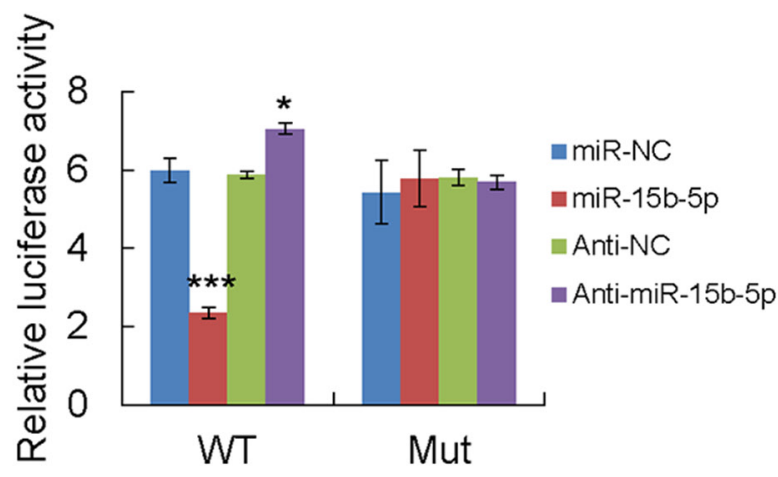

B

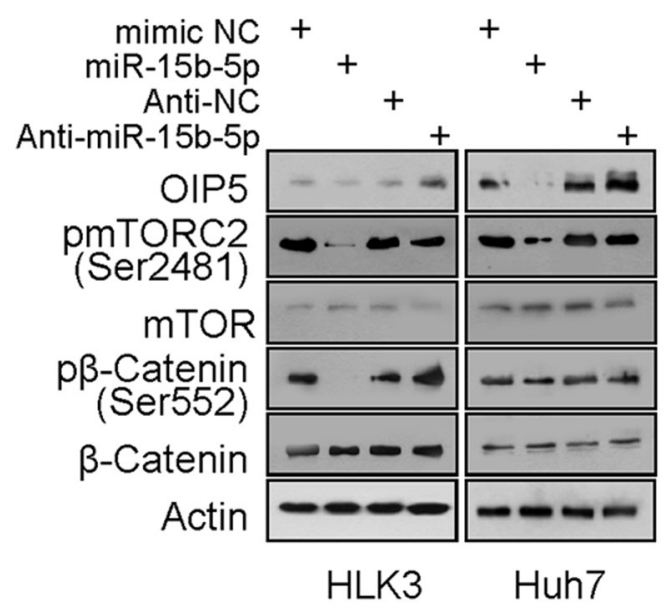

$\mathbf{E}$

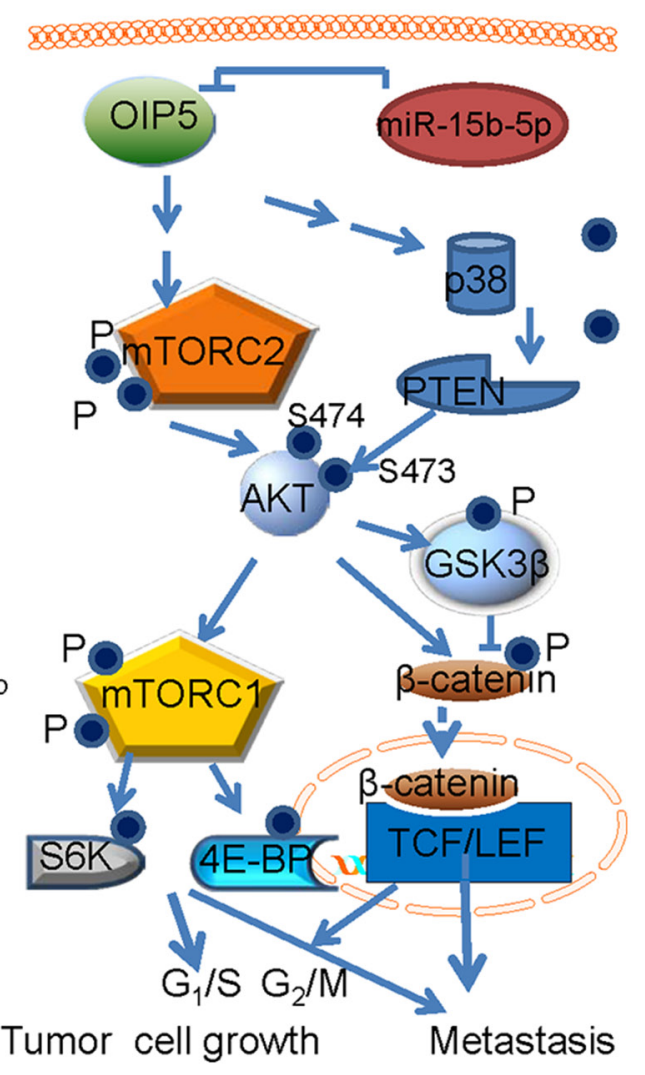

Figure 7: OIP5 is a direct target of miR-15b-5p. A. HLK3 and Huh7 cells transiently transfected with $5 \mathrm{nM}$ miR negative control (NC) or miR-15b-5p mimics, and $50 \mathrm{nM}$ anti-miR negative control (Anti-NC) or miR-15b-5p inhibitor, for 48 h. Decreased OIP5 mRNA levels were observed in HLK3 and Huh7 cells transfected with the miR-15b-5p mimic, while increased OIP5 mRNA expression was observed in HLK3 and Huh7 cells transfected with miR-15b-5p inhibitor. $* P<0.05$; $* * P<0.01$; $* * * P<0.001$. B. Effects of miR-15b-5p on OIP5 expression and on the activation of downstream molecules. C. Wild type and mutant putative miR-15b-5p binding sequence in the 3'UTR of OIP5 mRNA. D. Relative luciferase activity was significantly decreased by cotransfection of wild type (WT) pGL3-OIP5 3'UTR with miR-15b-5p mimics or anti-miR-15b-5p into HEK293T cells, but not by cotransfection of a mutant (Mut) pGL3-OIP5 3'UTR with miR-15b-5p mimics. ${ }^{* * *} P<0.001$. E. Schematic model of the upstream (mTORC2 and PTEN) and downstream (mTORC1 and $\beta$-catenin) signaling pathways of AKT in OIP5 expressed cells. 
and cyclin D1 [30]. In HCC, one of the major causes of WNT activation is $\beta$-catenin mutation with a rate between 20 and $40 \%$ [31, 32]. However, our data show that OIP5 enhances the nuclear translocation of $\beta$-catenin through the phosphorylation of GSK-3 $\beta$ at S9 and of $\beta$-catenin at S522. Consequently, OIP5 activates $\beta$-catenin signaling.

AKT induction also triggers activation of the mTORC1/p70S6K cascade, a pathway that contributes to cell growth and survival [33]. mTOR is activated both via phosphorylation by AKT and through inactivation of mTOR inhibitor TSC2. Although the activation of mTOR is limited to a subset of human HCCs, AKT deregulation has a pivotal role in human liver cancer [34]. Accordingly, the activation of the AKT/mTORC1 pathway in the livers of mice induces lipogenesis and tumor development [35]. We initially proposed that OIP5 expression itself can activate the AKT/mTORC1 pathway, which prominently contributes to tumor cell proliferation in association with $\mathrm{G}_{1} / \mathrm{S}$ cell cycle progression and, to a lesser extent, tumor metastasis. OIP5 expression resulted in phosphorylation of AKT at S473 and S474, which is linked to activation of the mTORC1 pathway. In addition, there is evidence of antitumor activity following mTOR blockade after treatment with rapamycin and its analogs in experimental models of HCC [36, 37].

miR-15 acts on proteins regulating cell cycle regulation, proliferation, and stem cell renewal [38]. miR-15b is a cell cycle regulator in glioma [12]. Our present study showed that miR-15b-5p directly binds to the 3'UTR of OIP5 and downregulates its mRNA and protein expression. miR-15b-5p was inversely regulated in a cyclic manner compared with OIP5 mRNA levels, and plays a role in the inhibition of oncogenic signaling of OIP5 through targeting mTORC 1 and $\beta$-catenin, as well as functioning as a tumor suppressor.

In summary, OIP5 seems to be involved in HCC growth and metastasis through the mTORC1 and $\beta$-catenin signaling pathways. miR-15b-5p efficiently inhibits OIP5mediated oncogenic signaling in HCC. Therefore, OIP5 may serve as a novel therapeutic target in HCC.

\section{MATERIALS AND METHODS}

\section{Tissue acquisition}

Surgically-resected HCC and matched nontumor tissues were collected according to a protocol conforming to the ethical guidelines of the Institutional Review Board (IRB) of Chonbuk National University Hospital. The Research Ethics Committee of Chonbuk National University Hospital approved the study. Written informed consent was obtained from each patient. Pathologists histologically confirmed HCC and non-tumor tissues.

\section{Cell lines}

HCC cell lines, including HepG2, Hep3B, SKHEP-1, and Alexander cells as well as immortalized cell lines such as Chang liver and THLE2 were procured from the ATCC (Manassas, VA, USA). Huh7 cells were acquired from the Korean Cell Line Bank (KCLB, Seoul, South Korea). HLK2, HKK2, HLK4, HLK1, HLK5, HKK1, HLK6, and SH-J1 cells as well as immortalized cell line HLK3 were established in our laboratory from surgical specimens of HCC patients [39]. The cells lines, with the exception of THLE2, were cultured at $37^{\circ} \mathrm{C}$ in a humidified atmosphere containing $5 \% \mathrm{CO}_{2}$ in DMEM medium supplemented with $10 \%$ fetal bovine serum (FBS; Gibco-BRL, Carlsbad, CA, USA), $1 \%$ penicillin and streptomycin solution (Sigma), $3 \mathrm{mM}$ taurine, and $25 \mathrm{mM}$ HEPES (Invitrogen). THLE2 cells were cultured using a BEGM bullet kit (Clonetics, Walkersville, MD, USA).

\section{Real-time PCR}

RNA prepared from dissected tissues was precipitated with isopropanol and dissolved in DEPCtreated distilled water. Reverse transcription (RT) was performed using $2 \mu \mathrm{g}$ total RNA, $50 \mu \mathrm{M}$ decamer, and $1 \mu \mathrm{l}$ (200 units) RT-PCR Superscript II (Invitrogen) at $37^{\circ} \mathrm{C}$ for $50 \mathrm{~min}$. Specific primers for OIP5 were designed employing the Primerdepot website (http://primerdepot. nci.nih.gov/): OIP5 (accession No. NM_007280), 5'TGGCATTGAAGGTTCACTCA -3' (forward), and 5'AGGGCAGCATGGGTAGAATA -3' (reverse). A control $18 S$ ribosomal RNA primer from Applied Biosystems was used as the invariant control. The real-time RT-PCR reaction mixture, which consisted of $10 \mathrm{ng}$ reversetranscribed total RNA, $167 \mathrm{nM}$ forward and reverse primers, and $2 \times$ PCR master mixture in a final volume of $10 \mu \mathrm{l}$, was placed in 384-well plates and analyzed using the ABI Prism 7900HT Sequence Detection System (Applied Biosystems, Foster City, CA, USA).

\section{Immunoblotting}

To prepare whole cell lysates, cells were lysed on ice in RIPA lysis buffer (50 mM Tris-HCL [pH 7.4], $150 \mathrm{mM} \mathrm{NaCl}, 0.25 \%$ sodium deoxycholate, $1 \% \mathrm{NP}-$ 40, $1 \mathrm{mM}$ EDTA, $0.1 \%$ sodium dodecyl sulfate [SDS], $1 \mathrm{mM}$ PMSF, $10 \mu \mathrm{g} / \mathrm{ml}$ leupeptin, $10 \mu \mathrm{g} / \mathrm{ml}$ aprotinin). Thirty micrograms of protein of cell or tissue lysates was resolved by SDS-PAGE then transferred to a nitrocellulose membrane (Millipore, Billerica, MA, USA), which was then blocked with Tris-buffered saline solution containing $0.05 \%$ Tween 20 for $1 \mathrm{~h}$ at room temperature. The blots were then probed with the relevant antibodies overnight at $4{ }^{\circ} \mathrm{C}$, washed, and probed again with species-specific secondary antibodies coupled to horseradish peroxidase (Sigma). Immunoreactivity was assessed using an ECL prime Western blotting kit (Amersham Pharmacia 
Biotech, Buckinghamshire, UK), according to the manufacturer's instructions. For nuclear and cytosolic cellular fractionation, both fractions were isolated from HLK3 cells using the commercially available NE-PER Nuclear and Cytoplasmic Extraction Reagents from Thermo Scientific (Rockford, IL, USA), following the manufacturer's protocol. For the thymidine-aphidicolin double-block, 25\% confluent HeLa cells were cultured in the presence of $2 \mathrm{mM}$ thymidine for $14 \mathrm{~h}$ and released into fresh medium for $14 \mathrm{~h}$. They were then incubated in the presence of $2 \mu \mathrm{g} / \mathrm{ml}$ aphidicolin for $14 \mathrm{~h}$ before release into fresh medium, as described previously [40].

Anti-human phospho-Akt (Ser473), AKT, phosphoGSK-3 $\beta$ (Ser9), phospho-Cdc25C (Ser216), phosphoCdc2 (Tyr15), phospho-ERK, ERK, phospho-mTOR (Ser2448), phospho-mTOR (Ser2481), mTOR, phospho4E-BP1(Thr37/46), 4E-BP1, phospho-p70s6k (Thr389), p70s6k, phospho- $\beta$-catenin (Ser552), phospho-PDK1 (Ser241), PDK1, phospho-PI3K (Y458/Y199), and PI3K antibodies were purchased from Cell Signaling Technology (Danvers, MA, USA). Polyclonal anti-human Cdc25C (C-20), Cdc2, cyclin A (H-432), cyclin B1 (H433), cyclin D1 (C-20), cyclin E (C-19), GSK-3 $\beta$ (L-17), $\beta$-catenin (H-102), Lamin B (C-20), Cytokeratin 18 (C04), Cytokeratin 8 (M20), N-cadherin (H69), Desmoplakin I/II (G20), c-Myc (9E10), GFP (FL), P21 (C-19), CDK2 (M2), CDK4 (H-22) and CDK6 (C-21) antibodies were purchased from Santa Cruz Biotechnology Inc. (Santa Cruz, CA). Polyclonal anti-OIP5 antibody (12142-1-AP) was obtained from Proteintech (Chicago, IL). Monoclonal anti- $\beta$-actin (AC-15), anti- $\alpha$-tubulin (DM1A), anti- $\alpha$ SMA and anti-Flag were obtained from Sigma (St. Louis, MO). Rabbit cleaved poly(ADP-ribose)polymerase (PARP) polyclonal antibody, rabbit cleaved caspase-3 polyclonal antibody, and rabbit cleaved caspase- 9 polyclonal antibody were purchased from Cell Signaling (Danvers, MA), while mouse anti-caspase- 8 monoclonal antibody was obtained from BD Bioscience (San Jose, CA).

\section{Immunofluorescence and immunohistochemistry}

For immunofluorescence, cells were grown on glass coverslips and transfected with GFP-tagged OIP5 expression vector or empty vector control, fixed with $4 \%$ paraformaldehyde, permeabilized in phosphate-buffered saline (PBS) containing $0.2 \%$ Triton, and blocked with $1 \%$ bovine serum albumin (BSA). The slips were then incubated with rabbit polyclonal OIP5 antibody overnight at $4^{\circ} \mathrm{C}$, washed, and incubated with tetramethylrhodamine isothiocyanate isomer R (TRITC)-conjugated goat antirabbit immunoglobulin. After a final wash, the cells were stained with $1 \mathrm{mg} / \mathrm{ml}$ Hoechst 33258 for $15 \mathrm{~min}$ to visualize the nuclei, and mounted with mounting medium for fluorescence (Vector Laboratories, Burlingame, CA, USA). The cells were examined using a laser scanning LCM 510 microscope (Carl Zeiss, Jena, Germany). For the experiment regarding $\beta$-catenin nuclear translocation, HLK3 cells were transiently co-transfected with Myctagged OIP5 and GFP-tagged $\beta$-catenin and then processed for IF.

Immunohistochemical staining was performed on formalin-fixed, paraffin-embedded tissue sections cut to 4- $\mu \mathrm{m}$ thickness. After rehydration, a deparaffinized section was pretreated by microwave epitope retrieval $(750 \mathrm{~W}$ for $15 \mathrm{~min}$ in $10 \mathrm{mM}$ citrate buffer; $\mathrm{pH}$ 6.0). Before applying primary antibody, endogenous peroxidase activity was inhibited with 3\% hydrogen peroxide, and a biotin with bovine albumin blocking step was performed. The primary antibody for OIP5 was detected using a secondary biotinylated antibody and a streptavidin-horseradish peroxidase conjugate following the manufacturer's instructions (DAKO, Glostrup, Denmark).

\section{shRNA expressing lentiviral vectors, transduction, and FACS analysis}

A lentivirus vector encoding an shRNA targeting OIP5 (shO-1 target sequence: 5'-CCGGGCATCAGAGA TGGATATTCAACTCGAGTTGAATATCCATCTCTGA TGCTTTTTG-3' and shO-2 target sequence: 5'-CCGGCC ATGTGTCCTCTGATCTAAACTCGAGTTTAGATCAG AGGACACATGGTTTTTG-3'), or an shRNA non-target control (NT sequence: 5'-CCGGCAACAAGATGAAGA GCACCAACTCGAGTTGGTGCTCTTCATCTTGTTG

TTTT-3') were used for transduction of Huh7 and HLK2 cells according to the manufacturer's instructions (SigmaAldrich, St Louis, MO, USA). In brief, $5 \times 10^{5}$ cells were incubated overnight in a $6-\mathrm{cm}$ plate and transduced with lentiviral particles at a multiplicity of infection (MOI) of 1 in the presence of $8 \mu \mathrm{g} / \mathrm{ml}$ of polybrene. Western blot analysis was performed to confirm the knockdown of OIP5 expression. For FACS analysis, cells $(2.5 \times$ $10^{5}$ ) were cultured in a six-well plate, transduced with lentiviruses for $18 \mathrm{~h}$, and treated with fresh medium. At 48 h post-transduction, cells were harvested, fixed with $70 \%$ cold ethanol, and stained with PI buffer ( $10 \mu \mathrm{g}$ propidium iodide and $1 \mathrm{mg} / \mathrm{ml}$ RNAse in $1.1 \%$ sodium citrate) at $37^{\circ} \mathrm{C}$ for $30 \mathrm{~min}$. The percentage of cells in each phase of the cell cycle was determined with a FACStar flow cytometer (Becton Dickinson, San Jose, CA, USA).

\section{Infection with recombinant adenovirus}

The human GFP-tagged OIP5 gene cloned into the pENTR 2B vector was cloned into a $\mathrm{pAd} / \mathrm{CMV} / \mathrm{V} 5$ destination vector using the LR reaction kit (Invitrogen, Carlsbad, CA, USA). pAd/CMV/V5-OIP5 linearized with PacI was transfected into 293A cells using Lipofectamine 2000 (Invitrogen). Adenoviral stock was prepared from the supernatant and was purified using an adenovirus purification kit (Clontech, Palo Alto, CA, USA). Adenoviruses encoding $\beta$-galactosidase (LacZ) served as a control. 


\section{3-(4,5-Dimethylthiazol-2-yl)2,5-diphenyl tetrazolium bromide (MTT) assay}

Viable cells were adjusted with medium to a concentration of $2 \times 10^{4}$ cells $/ \mathrm{ml}$ and $1 \mathrm{ml}$ per well was plated in 24-well plates. Cells were incubated for five days, then $50 \mu \mathrm{l}$ of 3-(4,5-dimethylthiazol-2-yl)-2,5diphenyl tetrazolium bromide $(5 \mathrm{mg}$ in $0.9 \%$ sodium chloride; Sigma) was added, and the cells were incubated for $4 \mathrm{~h}$ at $37^{\circ} \mathrm{C}$. After dissolving the precipitated dye in $200 \mu \mathrm{l}$ of dimethyl sulfoxide (Sigma) and $50 \mu \mathrm{l}$ of glycine buffer ( $\mathrm{pH} \mathrm{10.5),} \mathrm{the} \mathrm{absorbance} \mathrm{was} \mathrm{read} \mathrm{at} 540 \mathrm{~nm}$ in a Versa Max microtiter plate reader (Molecular Devices, Sunnyvale, CA, USA).

\section{Soft agar colony formation assay}

Cells were plated at a density of $1 \times 10^{5}$ cells per well in $60-\mathrm{mm}$ plates in growth medium containing $0.35 \%$ agar ( $3 \mathrm{ml}$ per well) on top of a layer of growth medium containing $0.7 \%$ agar $(5 \mathrm{ml}$ per well). Growth medium $(500 \mu \mathrm{l})$ with $10 \%$ FBS was added on top of the agar. The cell suspension was plated and cultured in a $37^{\circ} \mathrm{C}$ incubator for two weeks, after which viable colony formation was observed using an optical microscope.

\section{Phospho-proteome profiling}

Cells were rinsed with cold PBS and immediately solubilized in NP-40 lysis buffer (1\% NP-40, $20 \mathrm{mM}$ Tris- $\mathrm{HCl}$ [pH 8.0], $137 \mathrm{mM} \mathrm{NaCl}, 10 \%$ glycerol, $2 \mathrm{mM}$ EDTA, $1 \mathrm{mM}$ sodium orthovanadate, $10 \mu \mathrm{g} / \mathrm{ml}$ aprotinin, $10 \mu \mathrm{g} / \mathrm{ml}$ leupeptin) by rocking the lysates gently at $4^{\circ} \mathrm{C}$ for $30 \mathrm{~min}$. Following microcentrifugation at $14,000 \times \mathrm{g}$ for $5 \mathrm{~min}$, the supernatants were transferred into a clean tube, and sample protein concentrations were resolved using the Pierce Protein Assay Kit (Pierce, Rockford, IL, USA). Lysates $(500 \mu \mathrm{g})$ were diluted and incubated with the Human phospho-mitogen-activated protein kinase (MAPK) Array Kit (Proteome Profiler Array; R\&D Systems, Minneapolis, MN, USA) per the manufacturer's instructions. Array data were developed on X-ray film following exposure to chemiluminescent reagents.

\section{Animal experiments}

Four-week-old female BALB/c nude mice (BALB/ cByJ-Hfhl1 $1^{n u}$, Orient Co., South Korea) were used in the present experiment. All mice were fed ad libitum and received humane care under germ-free conditions in compliance with Korean NIH guidelines. In tumorigenicity experiments, Huh7 cells were transduced with a lentivirus vector encoding an shRNA targeting OIP5. These cells were harvested and $2 \times 10^{6}$ cells were resuspended in $60 \mu \mathrm{l}$ DMEM with $20 \mu \mathrm{l}$ Matrigel, and were then orthotopically injected into the left lobes of mouse livers. The mice were euthanized, and the tumor nodules and masses in the liver and mesentery were counted $(n=7)$.

\section{Luciferase reporter gene assay}

Transcriptional activity assays were measured with the Luciferase Assay System (Promega, Madison, WI, USA) according to the manufacturer's instructions. HEK293T cells were simultaneously cotransfected with OIP5 or a LacZ expression plasmid, in addition to a Cdc2luc, Cdc25C-luc, cyclin B1-luc, cyclin A-luc, cyclin D-luc, or cyclin E-luc reporter plasmid. Luciferase activity was measured using a Dual-Luciferase Reporter (DLR) Assay Kit (Promega) according to the manufacturer's instructions. Firefly and Renilla luciferase activity was gauged for normalization using a luminometer (Lumat LB9507, Berthold, Bad Wildbad, Germany). TCF/LEFdependent transcriptional activity was assessed using TOP flash/FOP flash reporter plasmids in HEK293T cells.

\section{miRNA profiling and data validation}

Total RNA that included small non-coding miRNA was isolated from HLK3 and Huh7 cells using an miRNEasy RNA isolation kit (Qiagen, Valencia, CA, USA) according to the manufacturer's instructions. RNA quality was determined using a Qubit 2.0 Fluorometer (Invitrogen). For each array, a minimum of $250 \mathrm{ng}$ total RNA was reverse transcribed using an miScript II RT Kit (Qiagen) according to the manufacturer's instructions. For miRNA profiling studies, a SYBR green-based pathway-focused miScript miRNA PCR Array (Qiagen) was used. The Human Cancer PathwayFinder miRNA PCR Array (384-well format, MIHS-102Z) enabled simultaneous detection of 84 miRNAs previously identified in human cancers, as well as appropriate housekeeping assays and RNA quality controls. The assay was performed according to the manufacturer's protocol. Real-time fluorescence was measured in 384well plates using the ABI Prism 7900HT Sequence Detection System (Applied Biosystems). Each condition was run in quadruplicate. Array analysis was performed using miScript miRNA PCR-array data analysis. Validation of miRNA profiling data was performed with an miScript SYBR Green PCR kit by real-time PCR estimation of miR-15b-5p. The RNU6-2 housekeeping miRNA was used for normalization.

\section{Transfection with miR- or inhibitor miR-15b-5p}

To overexpress or inhibit miRNAs, miRNA mimics (Qiagen \#MSY0000417) or inhibitor-miR (Qiagen \#MIN0000417) were transfected using Hiperfect transfection reagent (Qiagen) following the manufacturer's instructions. 


\section{miRNA target prediction}

The prediction of the OIP5 3' untranslated region (3'UTR) as an miRNA binding target was performed using TargetScan 6.2 (www.targetscan.org) and miRanda (www.microrna.org). To prepare luciferase constructs containing the 3'UTR of human OIP5, we cloned the 3'UTR of OIP5 into the pGL3-Control vector. The 3'UTR regions of OIP5 mRNA (NM_007280) matching miR$15 b-5 p$ sequences were synthesized via PCR and cloned into the pGL3 control vector (Promega) downstream of the luciferase open reading frame (ORF) after digestion with XbaI. The wide type primers were: forward, 5'-CT AGTCTAGATGCTAACGCACAATCGCTTAAAAT-3' and reverse, 5'-CTAGTCTAGAAGCCAATCTTTTTC AAGAAATGAC-3'. The mutant primers were: forward, 5'-TTCAACAACAGGAAAAAAATAGTCA-3' and reverse, 5'-TGACTATTTTTTTCCTGTTGTTGAA-3'. Cells were transfected with $50 \mathrm{nM}$ precursor miRNA miR-15b-5p along with the wild type or mutant OIP5-3'UTR-luciferase constructs. 48 hours after transfection, luciferase activity was measured using a dual-luciferase assay (Promega).

\section{Statistical analysis}

Statistical analyses were performed using Prism version 6 (Graphpad Software, San Diego, CA, USA). All experiments were performed in triplicate and data were expressed as mean \pm SD. Student's t-test was used for comparison between groups, and the Kruskal-Wallis test was used for overall comparisons. Clinicopathological data were analyzed using Mann-Whitney $U$ tests and chisquare tests. $P$ values $<0.05$ were considered significant.

\section{ACKNOWLEDGMENTS}

The authors gratefully acknowledge the excellent technical support of Yun-A Kim.

\section{CONFLICTS OF INTEREST}

The authors have no conflicts of interest to declare.

\section{GRANT SUPPORT}

This study was supported by the Biomedical Research Institute Fund, Chonbuk National University Hospital, Mid-Career Researcher Program, through a National Research Foundation of Korea (NRF) grant funded by the Ministry of Education, Science, and Technology (MEST) (2013R1A2A1A01009354) and the National R\&D Program for Cancer Control (0620220), Ministry for Health, Welfare, and Family Affairs, Republic of Korea.

\section{REFERENCES}

1. Williams JM, Chen GC, Zhu L, Rest RF. Using the yeast two-hybrid system to identify human epithelial cell proteins that bind gonococcal Opa proteins: intracellular gonococci bind pyruvate kinase via their Opa proteins and require host pyruvate for growth. Mol Microbiol. 1998; 27:171-186.

2. Fujita Y, Hayashi T, Kiyomitsu T, Toyoda Y, Kokubu A, Obuse C, Yanagida M. Priming of centromere for CENP-A recruitment by human hMis18alpha, hMis18beta, and M18BP1. Dev Cell. 2007; 12:17-30.

3. Naetar N, Hutter S, Dorner D, Dechat T, Korbei B, Gotzmann J, Beug H, Foisner R. LAP2alpha-binding protein LINT-25 is a novel chromatin-associated protein involved in cell cycle exit. J Cell Sci. 2007; 120:737-747.

4. Nakamura Y, Tanaka F, Nagahara H, Ieta K, Haraguchi N, Mimori K, Sasaki A, Inoue H, Yanaga K, Mori M. Opa interacting protein 5 (OIP5) is a novel cancer-testis specific gene in gastric cancer. Ann Surg Oncol. 2007; 14:885-892.

5. Chung KS, Jang YJ, Kim NS, Park SY, Choi SJ, Kim JY, Ahn JH, Lee HJ, Lim JH, Song JH, Ji JH, Oh JH, Song KB, et al. Rapid screen of human genes for relevance to cancer using fission yeast. J Biomol Screen. 2007; 12:568-577.

6. Chun HK, Chung KS, Kim HC, Kang JE, Kang MA, Kim JT, Choi EH, Jung KE, Kim MH, Song EY, Kim SY, Won M, Lee HG. OIP5 is a highly expressed potential therapeutic target for colorectal and gastric cancers. BMB Rep. 2010; 43:349-354.

7. Yazarloo F, Shirkoohi R, Mobasheri MB, Emami A, Modarressi MH. Expression analysis of four testis-specific genes AURKC, OIP5, PIWIL2 and TAF7L in acute myeloid leukemia: a gender-dependent expression pattern. Med Oncol. 2013; 30:368.

8. Gong M, Xu Y, Dong W, Guo G, Ni W, Wang Y, Wang Y, An R. Expression of Opa interacting protein 5 (OIP5) is associated with tumor stage and prognosis of clear cell renal cell carcinoma. Acta Histochem. 2013; 115:810-815.

9. Koinuma J, Akiyama H, Fujita M, Hosokawa M, Tsuchiya E, Kondo S, Nakamura Y, Daigo Y. Characterization of an Opa interacting protein 5 involved in lung and esophageal carcinogenesis. Cancer Sci. 2012; 103:577-586.

10. Wong CC, Wong CM, Tung EK, Au SL, Lee JM, Poon RT, Man K, Ng IO. The microRNA miR-139 suppresses metastasis and progression of hepatocellular carcinoma by down-regulating Rho-kinase 2. Gastroenterology. 2011; 140:322-331.

11. Ofir M, Hacohen D, Ginsberg D. MiR-15 and miR-16 are direct transcriptional targets of E2F1 that limit E2F-induced proliferation by targeting cyclin E. Mol Cancer Res. 2011; 9:440-447.

12. Xia H, Qi Y, Ng SS, Chen X, Chen S, Fang M, Li D, Zhao Y, Ge R, Li G, Chen Y, He ML, Kung HF, et al. MicroRNA$15 \mathrm{~b}$ regulates cell cycle progression by targeting cyclins in glioma cells. Biochem Biophys Res Commun. 2009; 380:205-210. 
13. Gautier J, Solomon MJ, Booher RN, Bazan JF, Kirschner MW. cdc25 is a specific tyrosine phosphatase that directly activates p34cdc2. Cell. 1991; 67:197-211.

14. Li QL, Gu FM, Wang Z, Jiang JH, Yao LQ, Tan CJ, Huang XY, Ke AW, Dai Z, Fan J, Zhou J. Activation of PI3K/AKT and MAPK pathway through a PDGFRbeta-dependent feedback loop is involved in rapamycin resistance in hepatocellular carcinoma. PLoS One. 2012; 7:e33379.

15. Wang C, Cigliano A, Delogu S, Armbruster J, Dombrowski F, Evert M, Chen X, Calvisi DF. Functional crosstalk between AKT/mTOR and Ras/MAPK pathways in hepatocarcinogenesis: implications for the treatment of human liver cancer. Cell Cycle. 2013; 12:1999-2010.

16. Shen YH, Zhang L, Utama B, Wang J, Gan Y, Wang X, Wang J, Chen L, Vercellotti GM, Coselli JS, Mehta JL, Wang XL. Human cytomegalovirus inhibits Akt-mediated eNOS activation through upregu lating PTEN (phosphatase and tensin homolog deleted on chromosome 10). Cardiovasc Res. 2006; 69:502-511.

17. Manning BD, Cantley LC. AKT/PKB signaling: navigating downstream. Cell. 2007; 129:1261-1274.

18. Mendoza MC, Blenis J. PHLPPing it off: phosphatases get in the Akt. Mol Cell. 2007; 25:798-800.

19. Sharma M, Chuang WW, Sun Z. Phosphatidylinositol 3-kinase/Akt stimulates androgen pathway through GSK3beta inhibition and nuclear beta-catenin accumulation. J Biol Chem. 2002; 277:30935-30941.

20. Fang D, Hawke D, Zheng Y, Xia Y, Meisenhelder J, Nika H, Mills GB, Kobayashi R, Hunter T, Lu Z. Phosphorylation of beta-catenin by AKT promotes beta-catenin transcriptional activity. J Biol Chem. 2007; 282:11221-11229.

21. Wang R, He G, Nelman-Gonzalez M, Ashorn CL, Gallick GE, Stukenberg PT, Kirschner MW, Kuang J. Regulation of Cdc25C by ERK-MAP kinases during the G2/M transition. Cell. 2007; 128:1119-1132.

22. Chin R, Earnest-Silveira L, Koeberlein B, Franz S, Zentgraf H, Dong X, Gowans E, Bock CT, Torresi J. Modulation of MAPK pathways and cell cycle by replicating hepatitis B virus: factors contributing to hepatocarcinogenesis. J Hepatol. 2007; 47:325-337.

23. Chun HK, Chung KS, Kim HC, Kang JE, Kang MA, Kim JT, Choi EH, Jung KE, Kim MH, Song EY, Kim SY, Won M, Lee HG. OIP5 is a highly expressed potential therapeutic target for colorectal and gastric cancers. BMB Rep. 2010; 43:349-354.

24. Datta SR, Brunet A, Greenberg ME. Cellular survival: a play in three Akts. Genes Dev. 1999; 13:2905-2927.

25. Cross DA, Alessi DR, Cohen P, Andjelkovich M, Hemmings BA. Inhibition of glycogen synthase kinase- 3 by insulin mediated by protein kinase B. Nature. 1995; 378:785-789.

26. Welsh GI, Foulstone EJ, Young SW, Tavare JM, Proud CG. Wortmannin inhibits the effects of insulin and serum on the activities of glycogen synthase kinase- 3 and mitogenactivated protein kinase. Biochem J. 1994; 303:15-20.
27. Behrens J. Control of beta-catenin signaling in tumor development. Ann N Y Acad Sci. 2000; 910:21-33; discussion 33-35.

28. Orford K, Crockett C, Jensen JP, Weissman AM, Byers SW. Serine phosphorylation-regulated ubiquitination and degradation of beta-catenin. J Biol Chem. 1997; 272:24735-24738.

29. Thompson MD, Monga SP. WNT/beta-catenin signaling in liver health and disease. Hepatology. 2007; 45:1298-1305.

30. Shtutman M, Zhurinsky J, Simcha I, Albanese C, D'Amico M, Pestell R, Ben-Ze'ev A. The cyclin D1 gene is a target of the beta-catenin/LEF-1 pathway. Proc Natl Acad Sci U S A. 1999; 96:5522-5527.

31. Cui J, Zhou X, Liu Y, Tang Z, Romeih M. Wnt signaling in hepatocellular carcinoma: analysis of mutation and expression of beta-catenin, T-cell factor-4 and glycogen synthase kinase 3-beta genes. J Gastroenterol Hepatol. 2003; 18:280-287.

32. Villanueva A, Newell P, Chiang DY, Friedman SL, Llovet JM. Genomics and signaling pathways in hepatocellular carcinoma. Semin Liver Dis. 2007; 27:55-76.

33. Hay N. The Akt-mTOR tango and its relevance to cancer. Cancer Cell. 2005; 8:179-183.

34. Ladu S, Calvisi DF, Conner EA, Farina M, Factor VM, Thorgeirsson SS. E2F1 inhibits c-Myc-driven apoptosis via PIK3CA/Akt/mTOR and COX-2 in a mouse model of human liver cancer. Gastroenterology. 2008; 135:1322-1332.

35. Calvisi DF, Wang C, Ho C, Ladu S, Lee SA, Mattu S, Destefanis G, Delogu S, Zimmermann A, Ericsson J, Brozzetti S, Staniscia T, Chen X, et al. Increased lipogenesis, induced by AKT-mTORC1-RPS6 signaling, promotes development of human hepatocellular carcinoma. Gastroenterology. 2011; 140:1071-1083.

36. Villanueva A, Chiang DY, Newell P, Peix J, Thung S, Alsinet C, Tovar V, Roayaie S, Minguez B, Sole M, Battiston C, Van Laarhoven S, Fiel MI, et al. Pivotal role of mTOR signaling in hepatocellular carcinoma. Gastroenterology. 2008; 135:1972-1983, 1983. e1971-1911.

37. Semela D, Piguet AC, Kolev M, Schmitter K, Hlushchuk R, Djonov V, Stoupis C, Dufour JF. Vascular remodeling and antitumoral effects of mTOR inhibition in a rat model of hepatocellular carcinoma. J Hepatol. 2007; 46:840-848.

38. Stevanato L, Sinden JD. The effects of microRNAs on human neural stem cell differentiation in two- and threedimensional cultures. Stem Cell Res Ther. 2014; 5:49.

39. Wang YP, Yu GR, Lee MJ, Lee SY, Chu IS, Leem SH, Kim DG. Lipocalin-2 negatively modulates the epithelialto-mesenchymal transition in hepatocellular carcinoma through the epidermal growth factor (TGF-beta1)/Lcn2/ Twist1 pathway. Hepatology. 2013; 58:1349-1361.

40. Sillje HH, Takahashi K, Tanaka K, Van Houwe G, Nigg EA. Mammalian homologues of the plant Tousled gene code for cell-cycle-regulated kinases with maximal activities linked to ongoing DNA replication. Embo j. 1999; 18:5691-5702. 